\title{
Identification of yeast genes that confer resistance to chitosan oligosaccharide (COS) using chemogenomics
}

Maria DLA Jaime ${ }^{1}$, Luis Vicente Lopez-Llorca², Ana Conesa ${ }^{3}$, Anna Y Lee ${ }^{4}$, Michael Proctor ${ }^{5}$, Lawrence E Heisler ${ }^{6,7}$, Marinella Gebbia ${ }^{6,7}$, Guri Giaever ${ }^{4,6,7}$, J Timothy Westwood $^{1 *}$ and Corey Nislow ${ }^{4,7,8^{*}}$

\begin{abstract}
Background: Chitosan oligosaccharide (COS), a deacetylated derivative of chitin, is an abundant, and renewable natural polymer. COS has higher antimicrobial properties than chitosan and is presumed to act by disrupting/ permeabilizing the cell membranes of bacteria, yeast and fungi. COS is relatively non-toxic to mammals. By identifying the molecular and genetic targets of COS, we hope to gain a better understanding of the antifungal mode of action of COS.

Results: Three different chemogenomic fitness assays, haploinsufficiency (HIP), homozygous deletion (HOP), and multicopy suppression (MSP) profiling were combined with a transcriptomic analysis to gain insight in to the mode of action and mechanisms of resistance to chitosan oligosaccharides. The fitness assays identified 39 yeast deletion strains sensitive to COS and 21 suppressors of COS sensitivity. The genes identified are involved in processes such as RNA biology (transcription, translation and regulatory mechanisms), membrane functions (e.g. signalling, transport and targeting), membrane structural components, cell division, and proteasome processes. The transcriptomes of control wild type and 5 suppressor strains overexpressing ARL1, BCK2, ERG24, MSG5, or RBA50, were analyzed in the presence and absence of COS. Some of the up-regulated transcripts in the suppressor overexpressing strains exposed to COS included genes involved in transcription, cell cycle, stress response and the Ras signal transduction pathway. Down-regulated transcripts included those encoding protein folding components and respiratory chain proteins. The COS-induced transcriptional response is distinct from previously described environmental stress responses (i.e. thermal, salt, osmotic and oxidative stress) and pre-treatment with these well characterized environmental stressors provided little or any resistance to COS.
\end{abstract}

Conclusions: Overexpression of the ARL 1 gene, a member of the Ras superfamily that regulates membrane trafficking, provides protection against COS-induced cell membrane permeability and damage. We found that the ARL1 COS-resistant over-expression strain was as sensitive to Amphotericin B, Fluconazole and Terbinafine as the wild type cells and that when COS and Fluconazole are used in combination they act in a synergistic fashion. The gene targets of COS identified in this study indicate that COS's mechanism of action is different from other commonly studied fungicides that target membranes, suggesting that COS may be an effective fungicide for drug-resistant fungal pathogens.

Keywords: Saccharomyces cerevisiae, Chitosan oligosaccharide, Antifungal resistance, ARL 1, Chemogenomics, Haploinsufficiency profiling (HIP), Homozygous profiling (HOP), Multi-copy suppression profiling (MSP),

Transcriptional analysis, Stress response

\footnotetext{
*Correspondence: t.westwood@utoronto.ca; corey.nislow@utoronto.ca

'Department of Cell and Systems Biology, University of Toronto, Mississauga,

Ontario, Canada

${ }^{4}$ Department of Molecular Genetics, University of Toronto, Toronto, Ontario,

Canada

Full list of author information is available at the end of the article
}

\section{Biomed Central}

(c) 2012 Jaime et al.; licensee BioMed Central Ltd. This is an Open Access article distributed under the terms of the Creative Commons Attribution License (http://creativecommons.org/licenses/by/2.0), which permits unrestricted use, distribution, and reproduction in any medium, provided the original work is properly cited. 


\section{Background}

Chitin is an abundant natural polymer, second only in biomass to cellulose [1]. It is a common constituent of crustacean exoskeletons and arthropod cuticles [2] as well as the cell walls of most fungi [2,3]. There is an estimated 10 gigatons of chitin recycled in nature each year [4].

Chitosan is a polymer of $\mathrm{N}$-glucosamine obtained by partial chitin N-deacetylation [1]. Acid hydrolysis or enzymatic cleavage of the glycosidic linkages of chitosan chains [5], yields shorter chains of $<1-10 \mathrm{KDa}$ chitosan oligosaccharides (COS). These polymers are less than 100 glucosamine monomers and are more water soluble and readily absorbed in vivo compared to chitosan [6].

Allan and Hadwiger [7] first showed the fungicidal effect of chitosan, and since then, several studies have examined chitosan sensitivity in different fungi [8-13]. Chitosan inhibits both hyphal growth and spore germination [14] and reduces toxin production by plant pathogenic fungi [15]. Recently, chitosan has been shown to increase conidiation in filamentous fungi at concentrations where hyphal growth was impaired [8]. Together these observations suggest that chitosan exerts its antifungal activity by multiple mechanisms.

We used COS in our study rather than chitosan because it is more soluble and biologically active. The biological activity of chitosan and COS is dependent on its molecular weight, degree of deacetylation and $\mathrm{pH}$ of the medium [16]. High degrees of deacetylation and an acidic $\mathrm{pH}$ (when most amino groups are in the free base form) yield the highest activity against susceptible fungi [17].

The antibiotic activity of chitosan and COS [16,18-20] is likely due to the permeabilization of bacterial plasma membranes [18,21]. Plasma membrane damage has also been suggested as an explanation of the fungicidal effects of chitosan in yeast and filamentous fungi [10,12,22,23]. Plasma membrane permeabilization by chitosan has also been detected (indirectly) in Saccharomyces cerevisiae, where deletion of genes encoding for proteins involved in maintaining plasma membrane integrity increased chitosan sensitivity [23]. Although it has been speculated that plasma membrane permeabilization by chitosan in bacteria and fungi is associated with the interaction between the positive amino groups of chitosan and the negative charges of phospholipids, no conclusive data are available $[10,12,18]$.

To gain a better understanding of the mode of action of small $(<6 \mathrm{kDa})$ chitosan oligosaccharides (COS5.44), and identify putative resistance mechanisms, we performed three chemogenomic screens [24,25]. These assays examined the effect of gene dosage to uncover bona fide targets of COS in yeast. Two chemogenomics assays interrogate the yeast deletion collection $(\sim 6000$ deletion strains) in a single culture in parallel. Each deletion strain in this collection contains a unique 20base-pair DNA tag used to quantify the fitness of individual strains using an oligonucleotide array [24,26]. Both essential heterozygous and non-essential homozygous diploids were assayed. The haploinsufficiency profiling (HIP) assay identifies genes that show increased drug sensitivity in heterozygous deletion strains. The heterozygous deletion strain that is most sensitive to a given compound often indentifies its target $[24,26]$. The homozygous profiling (HOP) assay identifies genes that buffer the drug target pathway and are required for resistance to the compound [24,26]. A multicopy suppression profiling (MSP) screen, where genes are overexpressed to identify those that confer resistance to the compound of interest was also performed [25]. The genes identified from the chemogenomic assays were individually validated to confirm their involvement in COS sensitivity or resistance. For five of the strains that conferred resistance when overexpressed, we performed a transcriptional analysis. The ARL1 (ADPribosylation factor-like 1) gene was identified in the HIP-HOP and MSP chemogenomics assays as being involved in yeast resistance to COS-5.44. This gene encodes a soluble GTPase that is a member of the Ras superfamily and has been shown to be involved in membrane traffic regulation [27,28]. ARL1 overexpression strains showed decreased COS-induced permeability compared to wild type cells. Because COS is a cell stress causing agent, we compared the transcriptional response induced by COS to those of other environmental stressors and ascertained whether an environmental stress pretreatment could provide resistance to COS. Finally, we evaluated whether a COS-resistant $A R L 1$ overexpressing strain is also resistant to other antifungal compounds.

\section{Results}

\section{Sensitivity to chitosan and COS-5.44 treatment in the yeast deletion pools}

A scheme summarizing the experiments and analyses performed in this study is shown in Figure 1. We first compared yeast sensitivity to deacetylated chitosan (approximately $70 \mathrm{kDa}, 80 \%$ deacetylated) and to chitosan oligosaccharide (COS) (5.44 kDa, 97\% deacetylated). COS (Additional file 1: Figure S1A) had considerably higher antifungal activity than chitosan at equivalent concentrations (Additional file 1: Figure S1B). Because of this, it is easier to more consistently manufacture this form, we decided to use COS as the antifungal agent. The heterozygous and homozygous yeast deletion collections were grown in YPD with $91.1 \mu \mathrm{g} / \mathrm{ml}$ COS-5.44, a concentration that inhibited yeast wild type growth by $10-20 \%$ compared with the control (Figure 2B). In the 


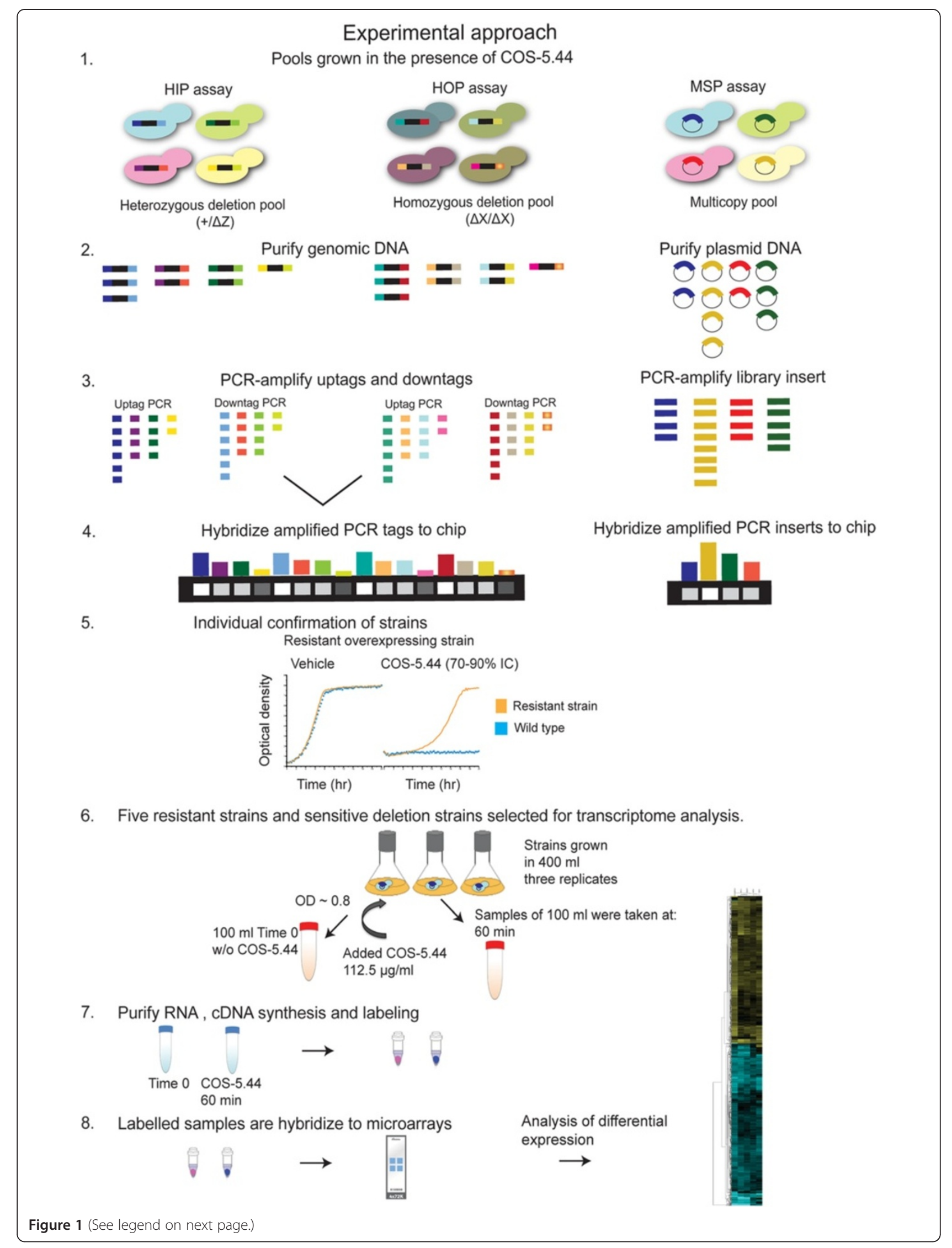


(See figure on previous page.)

Figure 1 Experimental approach used to identify and characterize genes that confer resistance to chitosan oligosaccharide (COS). Three chemogenomic assays were used: Haploinsufficiency profiling (HIP), homozygous profiling (HOP) and multicopy suppression profile (MSP). (1) Heterozygous, homozygous deletion pools and multicopy suppression pool were grown competitively in the presence of COS-5.44. If a gene is required to grow in the presence of COS, the corresponding deletion strain will grow more slowly and therefore will be underrepresented. Cells overexpressing a gene that suppresses sensitivity will growth faster and will be overrepresented in the MSP pool. (2) Genomic DNA was isolated from cells prior to and after the HIP-HOP assays, and plasmid purification from the COS treated MSP pool was carried out. (3) Barcodes were PCR amplified for HIP-HOP assays as well as the plasmid inserts of MSP. (4) PCR products (barcodes and plasmid inserts) were hybridized to a TAG4 array. Intensity of treatment samples is compared with intensity of a control sample to determine relative abundance ( fitness). (5) Sensitive deletion strains and constructed overexpressing strains were individually confirmed. (6) Five resistant overexpressing strains that were also sensitive as deletion strains were selected for transcriptome analysis. Overexpressing strains and vector control were grown in the presence of $\cos (112.5 \mathrm{\mu g} / \mathrm{ml})$ and cells were harvested before COS treatment and after 60 min of COS treatment. (7) RNA was isolated from harvested cells, cDNA synthesized and labelled with fluorescent dyes. (8) Labelled samples were hybridized to expression microarrays. Transcriptional changes were indentified by differential expression analysis. Figure modified from Ericson et al. (2010).

HIP-HOP assays, 39 yeast deletion strains sensitive to COS-5.44 were indentified (22 homozygous and 17 heterozygous; $\log 2$ ratio $\geq 3.5$, see Methods; Table 1 , Additional file 2: Table S1).

A previous global fitness analysis, similar to the HIPHOP assay we performed, identified 101 chitosan sensitive homozygous and three heterozygous deletion strains, [23]. Approximately $10 \%$ of the homozygous deletion strains found in their study were among the genes identified in our screen (ARL1, IMP2', APN1, RSC1, SNF8, DFG16, VPS66, YAP3, SSN8), but none of the three heterozygous deletions strains corresponded to those identified in our screen.

Biological processes (defined by Gene Ontological terms) associated with the COS-5.44 sensitive deletion strains were determined using gene set enrichment analysis (GSEA) [29]. The enriched processes included RNA biology (transcription, translation and regulatory mechanisms), membrane functions (e.g. transport and targeting), membrane structural components (e.g. proteins), cell division (spindle body and microtubules) and proteasome processes (structural and regulatory functions; Figure $2 \mathrm{C}, \mathrm{FDR} \leq 0.1$, see Methods). Similar GO terms showed altered fitness in the presence of chitosan in a similar fitness analysis [23].

To confirm whether the 39 deletion strains were sensitive to COS on their own, we tested each strain individually and found that $21(\sim 50 \%)$ were inhibited by COS (Table 1).

\section{Resistance to COS-5.44 treatment in the multicopy suppression profiling pool}

MSP assays involve the transformation of yeast with a multicopy suppression plasmid library containing random fragments of approximately $7 \mathrm{kbp}$ pieces of DNA. The MSP assay was performed with 101.25 - $250.0 \mu \mathrm{g} /$ $\mathrm{ml} \mathrm{COS}-5.44$ and it was determined that $112.5 \mu \mathrm{g} / \mathrm{ml}$ COS-5.44 inhibited wild type yeast growth by at least $70 \%$ (Figure 2B). Yeast containing suppression plasmids that provide resistance to $112.5 \mu \mathrm{g} / \mathrm{ml} \mathrm{COS}-5.44$ will expand more quickly than the rest of the yeast of the population. Genomic DNAs from a resistant population and a transformed but untreated population are extracted and hybridized to ORF microarrays to identify genes present in multicopies in the resistant population.

Two independent replicates of the MSP screen identified a total of 68 genes as putative suppressors of COS5.44 sensitivity (Additional file 1: Figure S2). The random genomic DNA fragments in the multicopy suppression plasmid library contain on average $2-3$ yeast genes per fragment [25]. Only one gene in each fragment is likely responsible for resistance; therefore we expected only $33-50 \%$ of these genes to be confirmed as suppressors of COS-5.44 (see below and Additional file 2: Table S2). There were 42 and 32 suppressing genes in replicates 1 and 2 respectively with only 6 genes in common (Additional file 1: Figure S2). The 6 genes were: PKR1, a V-ATPase assembly factor in the endoplasmic reticulum (ER) which functions with other V-ATPase assembly factors to efficiently assemble the V-ATPase membrane sector; $C O X 5 A$, subunit Va of cytochrome $\mathrm{c}$ oxidase, involved in mitochondrial electron transport; FLO1, a lectin-like cell wall protein involved in flocculation that binds to mannose on the surface of other cells; $V A C 7$, a vacuolar membrane protein involved in inheritance and vacuole morphology; RPL20A, a large ribosomal subunit protein; and MSG5, a dual specificity phosphatase protein required for maintenance of low level signaling through the cell integrity pathway which regulates and is regulated by Slt2p. Three of these genes, PKR1, VAC7 and MSG5, were also found to be sensitive to $C O S$ when tested as single heterozygous deletion strains. Among the suppressing genes found in replicate 2, ARL1, a gene encoding a GTPase protein, was identified. This gene was found to be sensitive to COS-5.44 as a deletion strain in the HIP-HOP assay (Table 1).

\section{Confirmation of COS suppressing strains}

After the identification of putative resistant strains we tested each strain individually. From the 68 candidate 


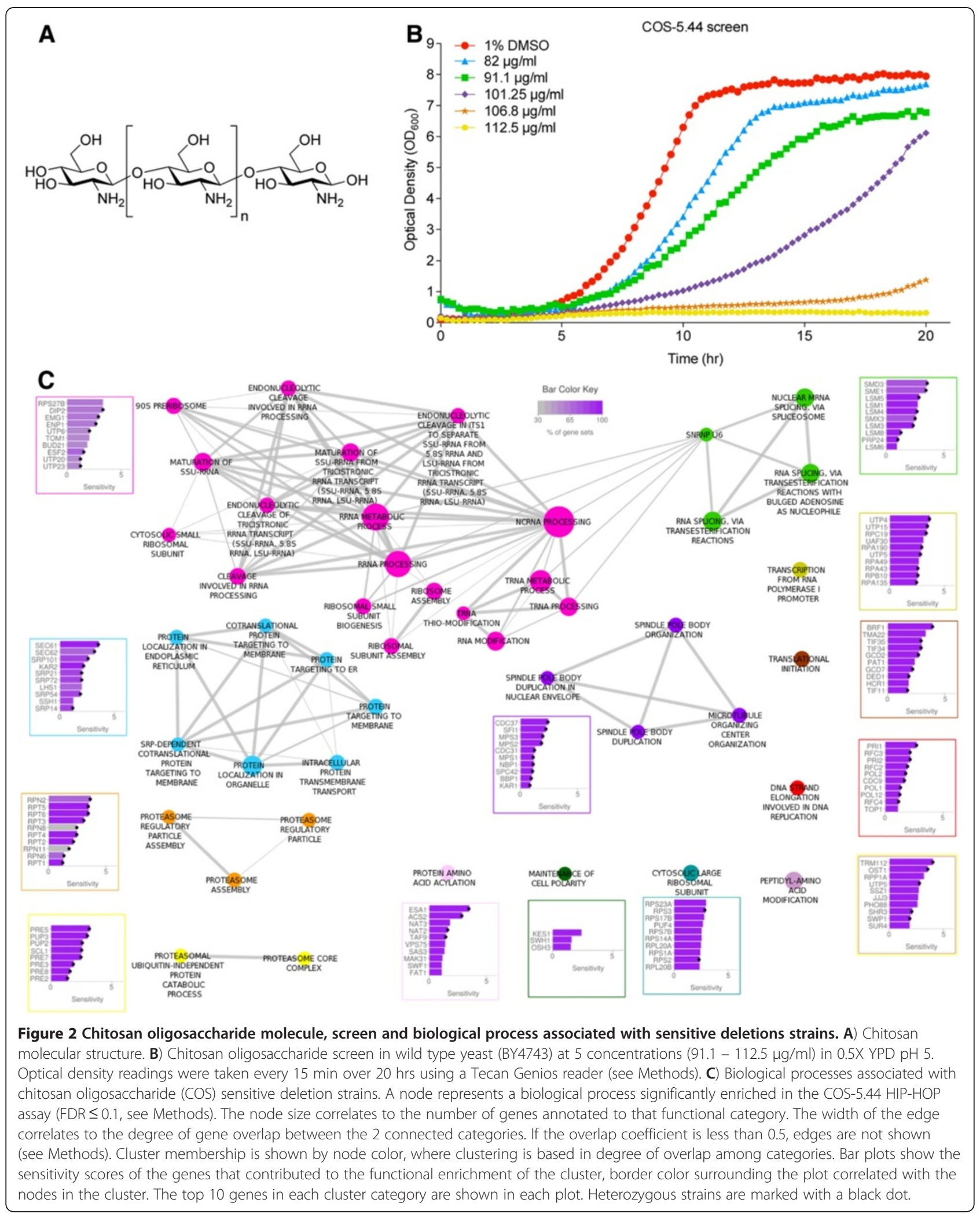


Table 1 Top 39 characterized sensitive deletion strains found in the HIP-HOP assays above 3.5 log 2 ratio

\begin{tabular}{|c|c|c|c|c|c|}
\hline probeid & $\begin{array}{l}\text { COS-5.44 } \\
(91.1 \mu \mathrm{g} / \mathrm{ml}) \\
\text { (log2ratio) }\end{array}$ & Gene & SGD_description & $\begin{array}{l}\text { Fitness } \\
\text { score }(a v g)^{2}\end{array}$ & $\begin{array}{l}\text { Deletion } \\
\text { pool source }\end{array}$ \\
\hline YBR 164C & 4.686 & ARL1 & $\begin{array}{l}\text { Soluble GTPase of the RAS superfamily, with a role in } \\
\text { regulation of membrane traffic mainly regulates } \\
\text { pottassium influx; similar to ADP-ribosylation factor. }\end{array}$ & 0.756 & HOM \\
\hline YBR257W & 3.534 & POP4 & $\begin{array}{l}\text { subunit of both RNase MRP, which cleaves pre-rRNA, } \\
\text { and nuclear RNase P, which cleaves tRNA precursors } \\
\text { to generate mature 5'ends; binds to the RPR1 RNA } \\
\text { subunit in RNase P. }\end{array}$ & 0.9963 & HET \\
\hline YDL060W & 3.769 & TSR1 & $\begin{array}{l}\text { Protein required for processing of } 205 \text { pre-rRNA in the } \\
\text { cytoplasm associates with pre-40S ribosomal particles. }\end{array}$ & 0.8887 & HET \\
\hline YDL213C & 5.101 & NOP6 & $\begin{array}{l}\text { rRNA-binding protein required for } 405 \text { ribosomal subunit } \\
\text { biogenesis; contains an RNA recognition motif (RRM). }\end{array}$ & 0.8854 & HOM \\
\hline YDR300C & 4.371 & PRO1 & $\begin{array}{l}\text { Gamma-glutamyl kinase, catalyzes the first step in proline } \\
\text { biosynthesis. }\end{array}$ & 0.8521 & HOM \\
\hline YDR320C & 3.571 & SWA2 & $\begin{array}{l}\text { Auxilin-like protein involved in vesicular transfort; clathrin- } \\
\text { binding protein required for uncoating of clathrin- } \\
\text { coated vesicles }\end{array}$ & 0.9621 & HOM \\
\hline YDR324C & 3.636 & UTP4 & $\begin{array}{l}\text { Subunit of } \mathrm{U} 3 \text { involved in production of } 18 \mathrm{~S} \text { rRNA, } \\
\text { assembly of small ribosomal subunit and transcription } \\
\text { of } 35 \mathrm{~S} \text { rRNA transcript, member of } \mathrm{t}-\mathrm{Utp} \text { subcomplex. }\end{array}$ & 0.761 & HET \\
\hline YDR389W & 4.281 & SAC7 & $\begin{array}{l}\text { GTPase activating protein (GAP) for Rho1p, involved } \\
\text { in signaling to the actin cytoskeleton, null mutations } \\
\text { suppress tor } 2 \text { mutations and temperature sensitive } \\
\text { mutations in actin; potential Cdc28p substrate. }\end{array}$ & 0.8768 & HOM \\
\hline YDR455C & 3.577 & YDR455C & Partially overlaps the verified gene YDR456W. & 0.9312 & HOM \\
\hline YGL045W & 4.229 & RIM8 & $\begin{array}{l}\text { Protein involved in proteolytic activation of Rim } 101 p \\
\text { in response to alkaline pH; interacts with ESCRT- } 1 \text { subunits } \\
\text { Stp } 22 p \text { and Vps } 28 p \text {; member of the arrestin-related } \\
\text { trafficking adaptor family. }\end{array}$ & 0.896 & HOM \\
\hline YGR056W & 3.72 & RSG1 & $\begin{array}{l}\text { Component of the RSC chromatin remodeling complex; } \\
\text { required for expression of mid-late sporulation-specific } \\
\text { genes. }\end{array}$ & 0.8656 & HOM \\
\hline YGR122W & 3.719 & YGR122W & $\begin{array}{l}\text { Probable ortholog of A. nidulans PalC, which is involved } \\
\text { in pH regulation and binds to the ESCRT-III complex; } \\
\text { null mutant does not properly process Rim } 101 \mathrm{p} \text { and } \\
\text { has decreased resistance to rapamycin. }\end{array}$ & 0.9913 & HOM \\
\hline YGR246C & 3.887 & BRF1 & $\begin{array}{l}\text { TFFIIIB B-related factor, one of three subunits of RNA } \\
\text { polymerase III transcription initiation factor TFFIIIB, } \\
\text { binds TFIIIC and TBP and recruits RNA pol III to promoters, } \\
\text { amino-terminal half is homologous to TFIIB. }\end{array}$ & 0.9782 & HET \\
\hline YHLO09C & 3.625 & YAP3 & Basic leucine zipper (bZIP) transcription factor. & 0.8854 & \\
\hline YIL019C & 3.59 & FAF1 & $\begin{array}{l}\text { Protein required to pre-rRNA processing and } 40 \mathrm{~S} \\
\text { ribosomal subunit assembly. }\end{array}$ & 0.9603 & HET \\
\hline YIL022W & 3.931 & TIM44 & $\begin{array}{l}\text { Essential component of the Translocase of the inner } \\
\text { Metochondrial membrane; tethers the import motor } \\
\text { and regulatory factors (PAM complex) to the translocation } \\
\text { channel (Tim23p-Tim17p core complex). }\end{array}$ & 0.8167 & HET \\
\hline YIL048W & 3.83 & NEO1 & $\begin{array}{l}\text { Putative aminophospolipid translocase (flippase) involved } \\
\text { in endocytosis and vacuolar biogenesis. }\end{array}$ & 1.0734 & HET \\
\hline YIL075C & 3.653 & RPN2 & $\begin{array}{l}\text { Subunit of the 26Sproteasome, substrate of the } \\
\text { N-acetyltransferase Nat1p. }\end{array}$ & 0.9832 & HET \\
\hline YIL154C & 4.315 & IMP2 & $\begin{array}{l}\text { Transcriptional activator involved in maintenance of } \\
\text { ion homeostasis and protection against DNA damage } \\
\text { caused by bleomycin and other oxidants. }\end{array}$ & 0.2516 & HOM \\
\hline YJL002C & 3.515 & OST1 & $\begin{array}{l}\text { Alpha subunit of the oligosaccharyltransferase } \\
\text { complex of the ER lumen, which catalyzes asparagine- } \\
\text { linked glycosylation of newly synthesized proteins. }\end{array}$ & 1.0555 & HET \\
\hline
\end{tabular}


Table 1 Top 39 characterized sensitive deletion strains found in the HIP-HOP assays above 3.5 log 2 ratio (Continued)

\begin{tabular}{|c|c|c|c|c|c|}
\hline YGL188C & 3.656 & BUD19 & $\begin{array}{l}\text { ORF overlaps the verified gene RPL39 by } 88 \% \text {; diploid } \\
\text { mutants displays a weak budding pattern phenotype } \\
\text { in a systematic assay. }\end{array}$ & 1.0087 & HOM \\
\hline YJR102C & 3.755 & VPS25 & $\begin{array}{l}\text { Component of the ESCRT-II complex, which is involved } \\
\text { in ubiquitin -dependent sorting of proteins into the } \\
\text { endosome. }\end{array}$ & 1.0011 & ном \\
\hline YKL114C & 4.271 & APN1 & $\begin{array}{l}\text { Apurinic/apyrimidinic endonuclease, 3'-repair diesterase } \\
\text { involved in repair of DNA damage by oxidation } \\
\text { and alkylating agents; also functions as a } 3^{\prime}-5^{\prime} \text { exonuclease } \\
\text { to repair 7,8-dihydro-8-oxodeoxyguanosine. }\end{array}$ & 0.8878 & HOM \\
\hline YKR024C & 3.506 & DPB7 & $\begin{array}{l}\text { Putative ATP-dependent RNA helicase of the dead } \\
\text {-box family involved in ribosomal biogenesis. }\end{array}$ & 0.9795 & ном \\
\hline YKR025W & 4.622 & SNF7 & $\begin{array}{l}\text { One of four subunits of the endosomal sorting complex } \\
\text { required for transport III (ESCRT-III); involved in the } \\
\text { sorting of transmembrane proteins into the multivesicular } \\
\text { body (MVB) pathway. }\end{array}$ & 0.8599 & HOM \\
\hline YLR100W & 3.929 & ERG27 & $\begin{array}{l}\text { 3-keto sterol reductase, catalyzes of the last three steps } \\
\text { required to removed two C- } 4 \text { methyl groups from an } \\
\text { intermediate in engosterol biosynthesis; mutants are } \\
\text { sterol auxotrophs. }\end{array}$ & 0.8809 & HET \\
\hline YLR147C & 3.525 & SMD3 & $\begin{array}{l}\text { Core Sm protein Sm D3; part of heteroheptameric complex } \\
\text { that is part of the spliceosomal U1, U2, U4, and U5 snRNPs; } \\
\text { homolog of human Sm D3. }\end{array}$ & 1.0582 & HET \\
\hline YLR223C & 3.633 & IFM1 & $\begin{array}{l}\text { Coactivator that regulates transcription of ribosomal protein } \\
\text { (RP) genes; recruited to RP gene promoters during optimal } \\
\text { growth conditions via Fhl1 p; subunit of CURI, a complex } \\
\text { that coordinates RP production and pre-rRNA processing. }\end{array}$ & 0.9691 & HET \\
\hline YLR378C & 3.539 & SEC61 & $\begin{array}{l}\text { Essential subunit of Sec61 complex (Sec61p, Sbh1p, and } \\
\text { Sss1p); with Sec63 complex forms a channel for SRP-dependent } \\
\text { protein import and retrograde transport of misfolded } \\
\text { proteins out of the ER. }\end{array}$ & 0.8717 & HET \\
\hline YNL025C & 3.581 & SSN8 & $\begin{array}{l}\text { Cyclin-like component of the RNA polymerase II holoenzyme, } \\
\text { involved in phosphorylation of the RNA polymerase II } \\
\text { C-terminal domain, in glucose repression and telomere } \\
\text { maintenance. }\end{array}$ & 0.823 & ном \\
\hline YNL287W & 3.66 & SEC21 & $\begin{array}{l}\text { Gamma subunit of coatomer, a heptameric protein complex } \\
\text { that together with Arf1p forms the COPI coat; involved in ER } \\
\text { to Golgi transport of selective cargo. }\end{array}$ & 0.8959 & HET \\
\hline YNR046W & 4.047 & TRM112 & $\begin{array}{l}\text { Subunit of tRNA methyltransferase (MTase) complexes in } \\
\text { combination with Trm9p and Trm11p; subunit of complex } \\
\text { with Mtq2p that methylates Sup45p (eRF1) in the temary } \\
\text { complex eRF1-eRF3-GTP. }\end{array}$ & 0.9906 & HET \\
\hline YOR014W & 3.844 & RTS1 & $\begin{array}{l}\text { B-type regulatory subunit of protein phospatase } 2 \mathrm{~A}(\mathrm{PP} 2 \mathrm{~A}) \text {; } \\
\text { homolog of the mammalian } \mathrm{B}^{\prime} \text { subunit of PP2A. }\end{array}$ & 0.9832 & ном \\
\hline YOR030W & 3.669 & DFG16 & $\begin{array}{l}\text { Probable multiple transmembrane protein, involved in } \\
\text { diploid invasive and pseudohyphal growth upon nitrogen } \\
\text { starvation; required for accumulation of processed Rim101p. }\end{array}$ & 1.0307 & Hом \\
\hline YOR080W & 4 & DIA2 & $\begin{array}{l}\text { Origin-binding F-box protein that forms an SCF ubiquitin } \\
\text { ligase complex with Skp1p and Cdc53p; plays a role in DNA } \\
\text { replication, involved in invasive and pseudohyphal growth. }\end{array}$ & 1.1312 & ном \\
\hline YOR117W & 3.506 & RPT5 & $\begin{array}{l}\text { One of the six ATPases of the } 195 \text { regulatory particle } \\
\text { ( } 26 S \text { proteasome) involved in the degradation of } \\
\text { ubiquintinated substrates; recruited to the GAL1-10 promoter } \\
\text { region upon induction of transcription; similar to human TBP1. }\end{array}$ & 0.8955 & HET \\
\hline YOR244W & 3.5 & ESA1 & Catalytic subunit of the histone acetyltransferase complex & 0.8716 & HET \\
\hline
\end{tabular}


Table 1 Top 39 characterized sensitive deletion strains found in the HIP-HOP assays above $\mathbf{3 . 5}$ log 2 ratio (Continued)

\begin{tabular}{|c|c|c|c|c|c|}
\hline PL002C & 3.679 & SNF8 & $\begin{array}{l}\text { Component of the ESCRT-II complex, which is involved in } \\
\text { ubiquitin-dependent sorting of proteins into the endosome; } \\
\text { appears to be functionally related to SNF7; involved in } \\
\text { glucose derepression. }\end{array}$ & 0.8925 & HOM \\
\hline PR139C & 3.643 & VPS66 & $\begin{array}{l}\text { Cytoplasmic protcin of unknown function involved in } \\
\text { vacuolar protcin sorting. }\end{array}$ & 8768 & M \\
\hline \multicolumn{6}{|c|}{ 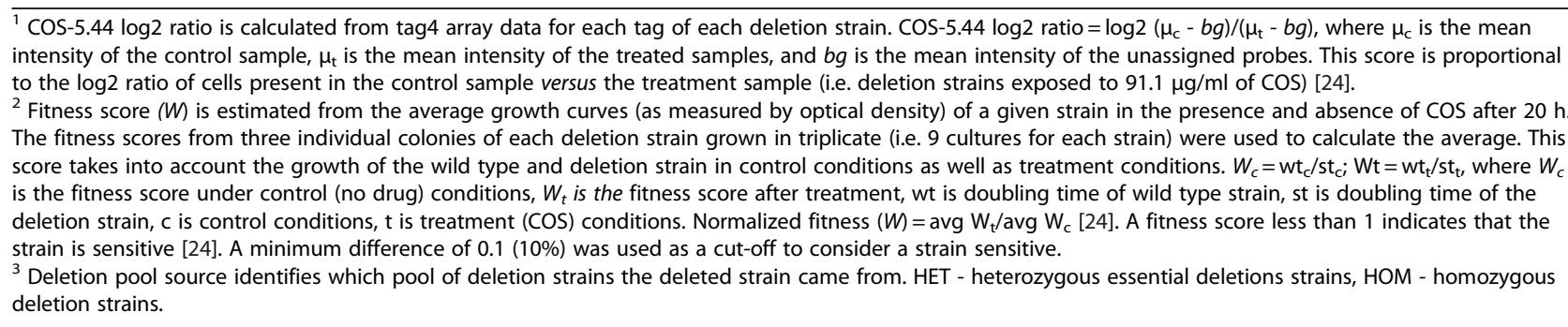 } \\
\hline
\end{tabular}

suppressor genes, 57 individual overexpressing/suppressing strains each containing a single putative resistance gene were obtained from a collection of ORFs whose expression is driven by native promoters [30] see Methods. Twenty-one $(\sim 31 \%)$ of the putative suppressor genes conferred resistance to COS-5.44 when tested in this manner (Table 2). COS-5.44 resistant overexpressing strains were able to grow in $112.5 \mu \mathrm{g} / \mathrm{ml}$ COS-5.44 while the wild type (transformed with an empty vector) was unable to grow (Figure 3B).

Among the confirmed genes that confer resistance to COS-5.44 were two essential genes: RBA50 (YDR527W), a gene whose protein product is involved in transcription, and ARP2 (YDL029W), a gene encoding actin related protein 2, a subunit of the Arp2/3 complex which is required for the motility and integrity of cortical actin patches. Among the remaining 19 nonessential genes, a diversity of functions were found, such as a sterol reductase, a heat shock protein, ADPribosylation factors, soluble GTPases, alpha tubulin, and a ubiquitin conjugation enzyme. Putative suppressors of COS antifungal action in yeast were all tested as heterozygous deletion strains and from the 21 resistant overexpressing strains, 11 were found to be sensitive when tested as heterozygous deletion strains (Table 2). Five genes that provided COS resistance when overexpressed or sensitivity as a heterozygous or homozygous deletion strain were selected for further study primarily based on the known or putative functions of the genes. More specifically we selected genes with roles in signalling pathways, cell or membrane integrity, or transcription regulation.

We selected the following 5 overexpressing strains: $A R L 1$, which encodes a GTPase involved in membrane trafficking, was selected because it was found in the HIP-HOP assay as a sensitive homozygous deletion strain and in the MSP assay as a multicopy suppressor. The other overexpressing strains we selected were:
$B C K 2$ and MSG5, which are both involved in cell integrity pathways; ERG24, a gene involved in ergosterol synthesis; and RBA50 (mentioned above). BCK2 is a SerThr rich protein with protein kinase $C$ activity that acts in signal transduction. Overexpression of $B C K 2$ can rescue defects in a $c w h 43 \Delta$ mutant that displays several cell wall defects [31]. BCK2 overexpression can also suppress the cell lysis defects seen when the kinases $M p k 1$ and Pck1 are deleted [32]. MSG5 encodes a protein phosphatase involved in cell cycle control through the dephosphorylation of MAPK and is required for restricting signaling by the cell integrity pathway in yeast [33]. The inhibition of MAPK signaling leads to inhibition of cell differentiation and cell division [34]. The functions of $A R L 1$ and ERG24 and their potential roles in chitosan resistance are described in more detail in the Discussion.

The fitness of all overexpressing strains compared to an empty vector control and the corresponding heterozygous deletion strains were assessed. In the presence of COS-5.44, the overexpressing strains always grew better than the vector control (Figure $3 \mathrm{~B}$, showing results of $A R L 1)$ and the corresponding deletion strain demonstrated reduced fitness (Figure 3D). In the absence of the COS-5.44, no growth differences were observed among each overexpressing strain or deletion strains (tested in triplicate) compared with the vector control, indicating the absence of inherent fitness defects (Figure $3 \mathrm{~A}$ and $3 \mathrm{C}$ ).

\section{Transcriptional response to COS}

To identify the transcriptional changes caused by exposure to COS-5.44, wild type (vector control) cells, were exposed to COS for $1 \mathrm{~h}$, total RNA extracted, and a microarray analysis was performed. A total of 335 genes were differentially expressed in response to COS-5.44 (P-value $<0.05$ and $\log 2$ fold change $>1$ or $<-1$ ).

A GSEA was performed for the entire transcription data set and among the up-regulated transcripts, we 
Table 2 Twenty-one yeast overexpression strains confirmed as suppresors of sensitivity to COS-5.44

\begin{tabular}{|c|c|c|c|c|c|c|}
\hline ORF & Gene & $\begin{array}{l}\text { Resistance } \\
\text { confirmed }\end{array}$ & $\begin{array}{l}\text { Fitness score of } \\
\text { resistance }(\text { avg })^{3}\end{array}$ & $\begin{array}{l}\text { Sensitivity confirmed } \\
\text { (HET deletion strain) }\end{array}$ & $\begin{array}{l}\text { Fitness score of } \\
\text { sensitivity (avg) }\end{array}$ & Description from SGD \\
\hline YBR164C & ARL1 $^{1}$ & yes & 1.870 & yes & 0.756 & $\begin{array}{l}\text { Soluble GTPase of the Ras superfamily, with a role in regulation of } \\
\text { membrane traffic mainly regulates potassium influx; } \\
\text { similar to ADP-ribosylation factor. }\end{array}$ \\
\hline YBR166C & TYR1 & yes & 1.381 & no & 1.035 & $\begin{array}{l}\text { Prephenate dehydrogenase involved in tyrosine biosynthesis, } \\
\text { expression is dependent on phenylalanine levels. }\end{array}$ \\
\hline YDL029W & ARP2 & yes & 1.609 & no & 1.023 & $\begin{array}{l}\text { Essential component of the Arp } 2 / 3 \text { complex involved in endocytosis } \\
\text { and membrane growth and polarity. A conserved actin nucleation } \\
\text { center required for the motility and integrity of actin patches. }\end{array}$ \\
\hline YDR171W & HSP42 & yes & 1.372 & no & 1.135 & $\begin{array}{l}\text { Small heat shock protein (SHSP) with chaperone activity involved } \\
\text { in cytoskeleton reorganization after heat shock; forms barrel-shaped } \\
\text { oligomers that suppress unfolded protein aggregation. }\end{array}$ \\
\hline YDR524C & AGE1 & yes & 1.783 & no & 1.106 & $\begin{array}{l}\text { ADP-ribosylation factor (ARF) GTPase activating protein (GAP) effector, } \\
\text { involved in the secretory and endocytic pathways. }\end{array}$ \\
\hline YDR527W & RBA50 ${ }^{1}$ & yes & 1.407 & yes & 0.899 & $\begin{array}{l}\text { Protein involved in transcription; interacts with RNA polymerase ॥ } \\
\text { subunits Rpb2p, Rpb3, and Rpb11p; has similarity to human RPAP1. }\end{array}$ \\
\hline YER048C & CAJ1 & yes & 1.845 & no & 0.995 & $\begin{array}{l}\text { Nuclear type II J heat shock protein of the of the E. coli dnaJ family, } \\
\text { binds, to non-native substrates for presentation to Ssa3p, may function } \\
\text { during protein translocation, assembly and disassembly. }\end{array}$ \\
\hline YER167W & $\mathrm{BCK} 2^{1}$ & yes & 1.365 & yes & 0.890 & $\begin{array}{l}\text { Protein rich in serine and threonine residues involved in protein kinase } \\
\text { C signaling pathway, which controls cell integrity; overproduction } \\
\text { suppresses pkc } 1 \text { mutations }\end{array}$ \\
\hline YJL046W & AIM22 & yes & 1.258 & no & 0.908 & $\begin{array}{l}\text { Putative lipoate-protein ligase, required along with Lip2 and Lip5 for } \\
\text { lipoylation of Lat1p and Kgd2p. }\end{array}$ \\
\hline YKL208W & CBT1 & yes & 1.265 & no & 0.930 & $\begin{array}{l}\text { a role in } 3^{\prime} \text { end processing of the COB pre-mRNA; displays genetic } \\
\text { interaction with cell cycle-regulated kinase. }\end{array}$ \\
\hline YLR193C & UPS1 & yes & 1.201 & no & 0.953 & $\begin{array}{l}\text { Mitochondrial intermembrane space protein that regulates mitochondrial } \\
\text { cardiolipin levels, null has defects in Mgm1 p processing, integrity of } \\
\text { mitochondrial inner membrane complexes; ortholog of human PRELI. }\end{array}$ \\
\hline YLR285W & NNT1 & yes & 1.448 & no & 1.184 & $\begin{array}{l}\text { Putative nicotinamide } \mathrm{N} \text {-methyltransferase, has a role in rDNA silencing } \\
\text { and in the lifespan determination. }\end{array}$ \\
\hline YML124C & TUB3 & yes & 1.763 & no & 1.227 & $\begin{array}{l}\text { Alpha-tubulin; associates with beta-tubulin (Tub2p) to form tubulin dimer, } \\
\text { which polymerizes to form microtubules; expressed at lower level than Tub1p. }\end{array}$ \\
\hline YMR123W & $\mathrm{PKR}^{2}$ & yes & 1.350 & yes & 0.866 & $\begin{array}{l}\text { V-ATPase assembly factor, functions with other V-ATPase assembly factors } \\
\text { in the ER to efficiently assemble the VATPase membrane sector (VO). }\end{array}$ \\
\hline YNL053W & MSG $^{1}$ & yes & 1.454 & yes & 0.874 & $\begin{array}{l}\text { Dual-specificity protein phosphatase; required for maintenance of a low } \\
\text { level of signaling through the cell integrity pathway, adaptive response to } \\
\text { pheromone; regulates and is regulated by Slt2p; dephosphorylates Fus } 3 p \text {. }\end{array}$ \\
\hline YNL054W & $V_{A C 7}{ }^{2}$ & yes & 1.387 & yes & 0.873 & $\begin{array}{l}\text { Integral vacuolar membrane protein involved in vacuole inheritance and } \\
\text { morphology; activities Fab1p kinase activity under basal conditions anfd } \\
\text { also after hyperosmotic shock. }\end{array}$ \\
\hline
\end{tabular}


Table 2 Twenty-one yeast overexpression strains confirmed as suppresors of sensitivity to COS-5.44 (Continued)

\begin{tabular}{|c|c|c|c|c|c|}
\hline YNL218W & $M S G 1^{2}$ & yes & 1.214 & yes & 0.899 \\
\hline YNL280C & ERG $24^{1}$ & yes & 1.275 & yes & 0.893 \\
\hline YNR057C & $\mathrm{BlO} 4^{2}$ & yes & 1.246 & yes & 0.885 \\
\hline YPL053C & $\mathrm{KTR}^{2}$ & yes & 1.616 & yes & 0.861 \\
\hline YPL106C & SSE1 $^{2}$ & yes & 1.253 & yes & 0.896 \\
\hline
\end{tabular}

Protein with DNA-dependent ATPase and ssDNA annealing activities involved in maintenance of genome; interacts functionally with DNA polymerase delta; homolog of human WHIP.

C-14 sterol reductase, acts in ergosterol biosynthesis; mutants accumulate the abnormal sterol ignosterol (ergosta-8, 14 dienol).

Dethiobiotin synthetase, catalyzes the third step in the biotin biosynthesis pathway; $\mathrm{BIO} 4$ is in a cluster of 3 genes $(\mathrm{BIO} 3, \mathrm{BIO} 4$, and $\mathrm{BIO} 5)$ that mediate biotin synthesis.

Probable mannosylphosphate transferase involved in the synthesis of core oligosaccharides in protein glycosylation pathway; member of the KRE2/MNT1 mannosyltransferase family.

ATPase that is a component of the heat shock protein Hsp90 chaperone complex; binds unfolded proteins; member of the heat shock protein 70 (HSP70) family; localized to the cytoplasm.

\section{Genes selected for transcriptomic analysis.}

${ }^{2}$ Overexpressing strains confirmed as suppressors when overexpressed and sensitive when tested as deletion strains.

${ }^{3-4}$ Fitness score $(W)$ is estimated from the average growth curves (as measured by optical density) of a given strain in the presence and absence of COS after $20 \mathrm{~h}$. Data shown corresponds to deletion strains exposed to $91.1 \mu \mathrm{g} / \mathrm{ml}$ and overexpressing strains to $112.5 \mu \mathrm{g} / \mathrm{ml}$ of chitosan oligosaccharide. The fitness scores from three individual colonies of each overexpressing or deletion strain grown in triplicate (i.e. 9 cultures for each strain) were used to calculate the average. This score takes into account the growth of the wild type and overexpressing or deletion strain in control conditions as well as treatment conditions. $W_{c}=w_{c} t_{c} / t_{c} i$

$\mathrm{Wt}=\mathrm{wt}_{\mathrm{t}} / \mathrm{st}_{\mathrm{t}}$, where $W_{c}$ is the fitness score under control (no drug) conditions, $W_{t}$ is the fitness score after treatment, $\mathrm{wt}$ is doubling time of wild type strain, st is doubling time of the overexpressing or deletion strain, $c$ is control conditions, $t$ is treatment $(C O S)$ conditions. Normalized fitness $(W)=a v g W_{t} / a v g ~ W_{c}$ [24]. A fitness score less than 1 indicates that the strain is sensitive, a fitness score above 1 indicates that the strain is resistant [24]. Means that the strain has a treatment induced growth defect, a minimum difference of 0.1 (10\%) was used as a cut-off to consider a strain sensitive. 


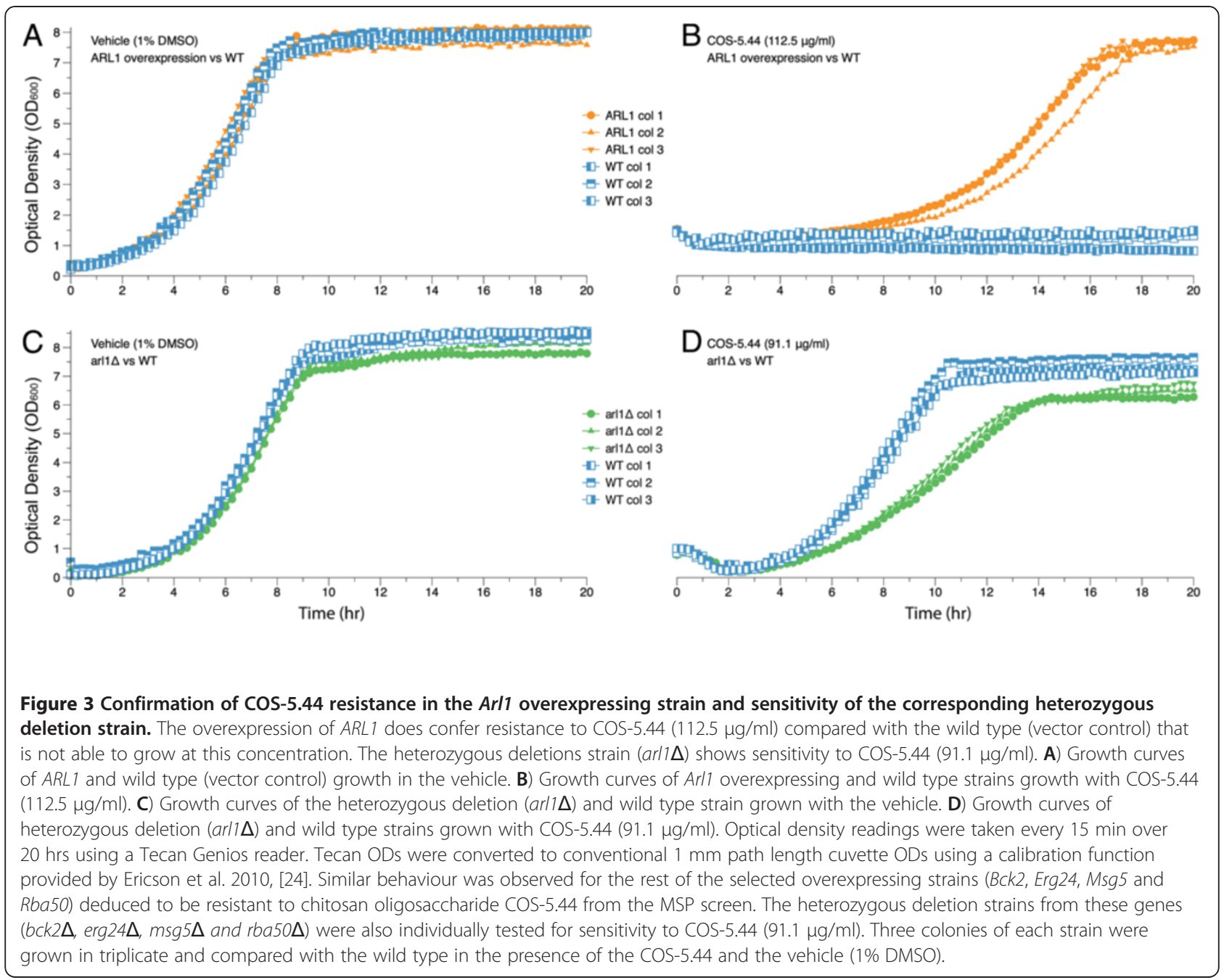

identified cellular respiration, ATP production, protein complex biogenesis, and mitochondria translation and organization as enriched biological processes $(P<0.005)$. For the down-regulated transcripts, the enriched terms included glycosylation, transmembrane transport, and sterol and lipid biosynthesis. For the overexpressing strains that provided resistance to COS (see below), the majority of these biological processes had the opposite characteristic (i.e. enriched biological processes among up-regulated transcripts in the wild type were enriched among down-regulated transcripts in the overexpression strains). A comparison of the transcriptional profiles of the COS-5.44 treated wild type cells in this study with the chitosan treated 60 min profile from another similar study, [22] was performed (Additional file 1: Figure S3, Additional file 2: Table S13). As might be expected, there was considerable overlap among enriched biological processes between the two studies (Additional file 1: Figure S3, Additional file 2: Table S13), and included such terms as cell wall organization, ATP production, and oxidative phosphorylation as being enriched among upregulated transcripts. Ribosome biogenesis and polyphosphate metabolic processes were enriched among down-regulated transcripts. There were also several biological processes that showed up as having opposite enrichments in the two studies. For example, sterol/ ergosterol/lipid biosynthesis was observed as a downregulated process in our study while these were upregulated in Zakrzewska and co-workers study. While it is not clear why some processes show opposite enrichments in the two studies, we do know that different types and amounts of anti-fungal agents were used, Zakrzewska et al. exposed the yeast cells to fragmented chitosan at an $\mathrm{IC}_{10}-15$ and in this study, cells were exposed to COS-5.44 at an $\mathrm{IC}_{70}-80$.

\section{Transcriptome analysis of the COS-5.44 resistant strains}

To gain a further understanding on the mode of action and mechanisms of resistance to COS, we performed a transcriptome analysis of the 5 overexpressing strains 


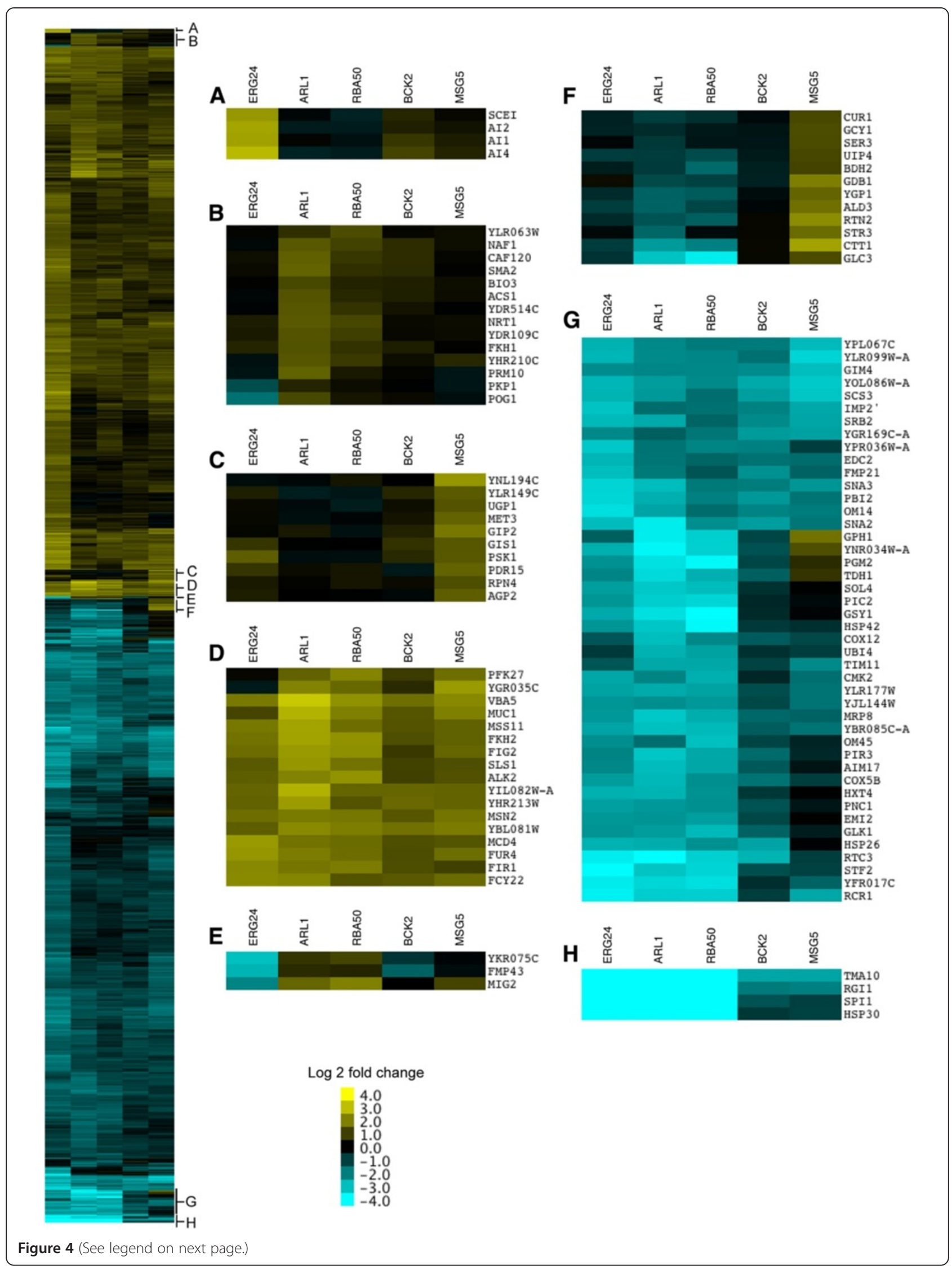


(See figure on previous page.)

Figure 4 Differentially expressed genes in COS-5.44 resistant yeast overexpressing strains in the presence of COS-5.44. One thousand two hundred and twenty genes showed a significant change in expression in at least one of the overexpressing strains compared with the wild type (P-value $\leq 0.05$ and $\log 2$ fold change $\geq 1$ or $\leq-1$ ). Clustering of the 1220 genes with significant change in expression was based in similarity (see methods). A-D) Subsets of up-regulated genes among the 5 overexpressing strains. E-H) Subsets of down-regulated genes among the 5 overexpressing strains.

known to increase resistance to COS-5.44 (data available in GEO under GSE32888). Each overexpressing strain and the wild type (vector control) were treated with COS-5.44 for $1 \mathrm{~h}$ or mock treated with vehicle alone and RNA was isolated from each sample. The RNA was converted to labeled cDNA and hybridized to NimbleGen expression microarrays (see Methods). We performed two sets of analyses. The first analysis was designed to find genes differentially expressed genes in each overexpression strain compared to wild type in the absence of COS in order to see if overexpression of the gene in question changed the transcriptional profile (and potentially the physiology or structure of the cell). The second analysis was designed to find differentially expressed genes in each overexpression strain compared to wild type in the presence of COS to see if the overexpression strains responded differently to COS than wild type.

In the first analysis, we identified 184 genes with differential expression in at least one of the 5 overexpressing strains compared with the wild type (vector control) without COS-5.44 treatment (Additional file 1: Figure S4, Additional file 2: Table S3; P-value $\leq 0.05$ and $\log 2$ fold change $\geq 1$ or $\leq-1$ ). Each of the 5 overexpressing strains showed increased expression of the gene contained in the transformation vector (Additional file 1: Figure S4 A-D). There was a subset of 13 highly up-regulated genes in the $A R L 1$ and $R B A 50$ strains (Additional file 1: Figure S4 A) including genes encoding heat shock proteins, acid phosphatases, inorganic phosphatases, and transmembrane transporters. Several genes involved in oxidative phosphorylation, amino acid and carbohydrate metabolic processes and biosynthesis, and mitochondrial ATP synthesis and electron transport were up-regulated (Additional file 1: Figure S4 D).

Transcriptome analysis following COS-5.44 treatment was performed and 1220 genes ( 589 up- and $\sim 631$ down-regulated) showed significant differential expression relative to the wild type under the same growth conditions (P-value $<0.05$ and $\log 2$ fold change $\geq 1$ or $\leq \_1$, Additional file 2: Table S4) in at least one of the 5 overexpressing strains (Figure 4). Significantly over represented biological processes identified by enrichment analyses $[35,36]$ in the 589 differentially upregulated genes included transcription, cell cycle, protein modification, stress response and RAS signal transduction (Figure 4A-E). Down-regulated genes were enriched for biological processes included protein folding, protein complex assembly, and respiratory chain complex genes (Figure 4F-H).

The primary biological processes associated with the 5 overexpression strains in the presence of COS (Table 2) were: membrane signalling functions ( $A R L 1, B C K 2$, MSG5), transcription (RBA50) and ergosterol synthesis (ERG24). To gain insight into the potential mechanisms of COS resistance for each overexpressed gene, enrichment maps were constructed from the entire transcription data set, GSEA analyzed, for each of the COS treated overexpressed strains (Figure 5 and Additional file 1: Figures S5- S9). Genes that were down-regulated to various degrees in all 5 strains were associated with processes such as cell energy generation (mitochondrial biology, ATP metabolism, energy storage metabolites) and associated by-products (oxidative stress). Most overexpressing strains (ARL1, ERG24 and RBA50) displayed up-regulated genes involved in cell cycle progression (mitosis/meiosis, chromatin dynamics and modification and sporulation) and transcription. Taken together these results suggest that the overexpression resistant strains had an overall reduction in energy production and an increase in cell proliferation in response to COS-5.44 perturbation compared to wild type cells.

We confirmed some of the global transcriptional changes by qRT-PCR. ARL1 overexpression was confirmed in Arl1 overexpressing strains. For all of the genes selected, the qRT-PCR results were always in the same direction as the microarray results (i.e. increased transcript levels for a given gene found using microarrays was also found to be increased by qRT-PCR) but the dynamic range for the transcript changes was greater in the qRT-PCR assays. COS-5.44 treatment increased levels of expression in the Arl1 overexpressing strain for FIG2, MUC1,VBA5 and YJU2 with the qRT-PCR transcript levels being 50 - 200\% higher when compared with the microarray data. Decreased transcript levels were confirmed for CMD1, COX5B, HSP30, RCR1 and UBI4, using qRT-PCR (Additional file 1: Figure S10).

\section{ARL1 overexpression reduces COS-induced membrane permeabilization}

A Sytox permeability assay was performed in the wild type (BY4743) and ARL1 strain after overnight growth in 


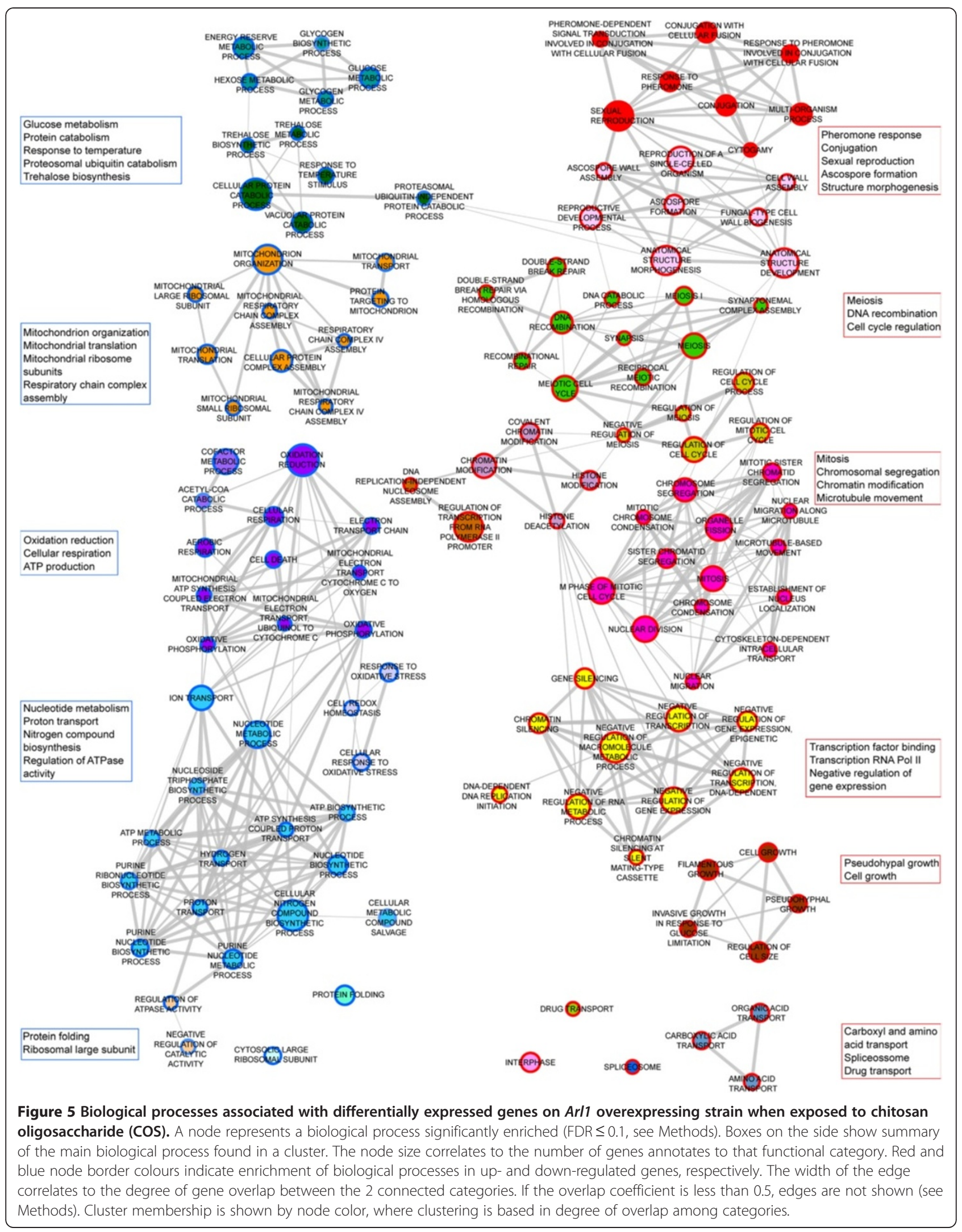




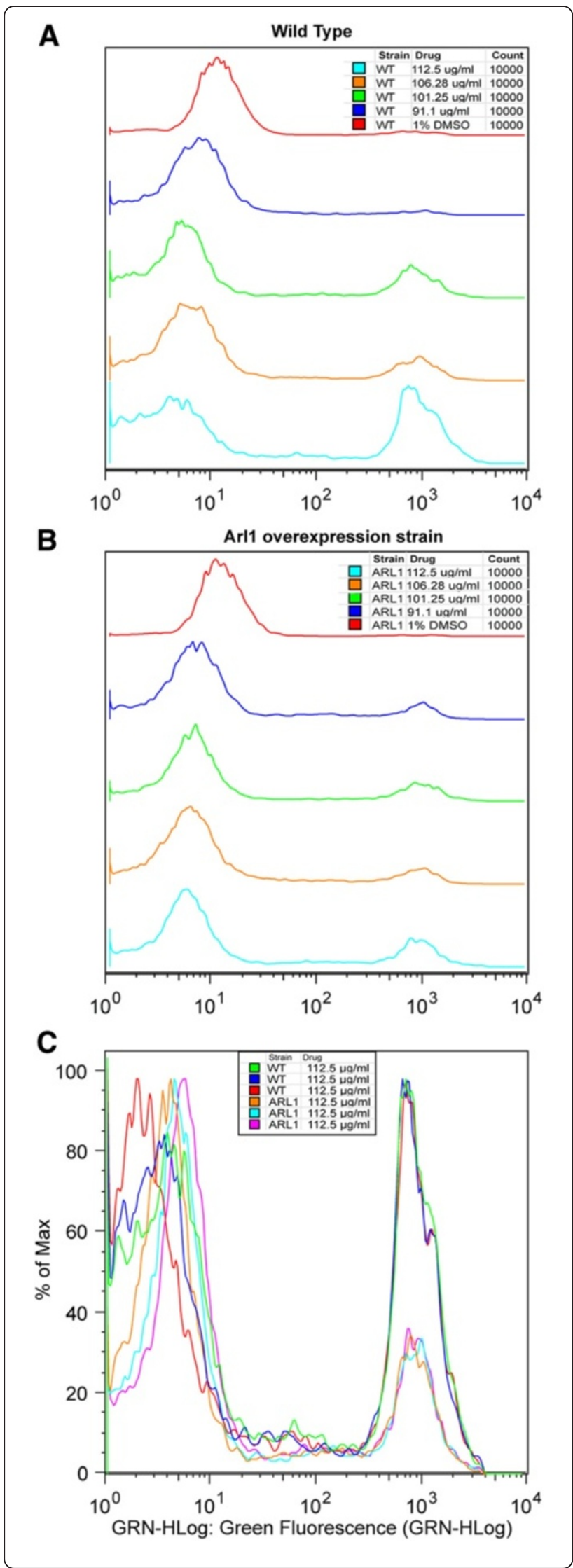

Figure 6 Sytox cell permeability assay of COS-5.44 resistant Arl1 overexpressing strain vs. vector control (BY4743). A) Vector control (BY4743) shows significantly higher cell membrane permeability compared with overexpressing strain Arl1 (B) after treatment with chitosan oligosaccharide (COS-5.44). A large increase in cell membrane permeability is observed in the wild type as chitosan oligosaccharide concentration is increased (A). The first peak (left) in the graph corresponds to the background fluorescence and the second peak (right) corresponds to the Sytox signal observed inside the cell due to nucleic acid binding. C) Overlay of 3 replicates of each strain Sytox assay after exposure to $112.5 \mu \mathrm{g} / \mathrm{ml}$ COS-5.44. Student $t$-test of $C$ ) data, P-value $<0.0101$

YPD with COS-5.44 to assess cell membrane permeability [37] see Methods. Sytox Green fluoresces once bound to nucleic acids. It only enters cells with compromised plasma membranes and is excluded from live cells with an intact plasma membrane. Wild type cells treated with COS-5.44 were Sytox-positive indicating that COS treatment causes membrane permeability (Figure 6A and $6 \mathrm{C})$. There was a dose dependent increase in the intracellular Sytox fluorescence signal as a function of COS concentration (Figure 6A). Although there was some Sytox signal in the Arl1 overexpressing strain, it was significantly lower than that in the wild type at the highest concentration of COS tested $(112.5 \mu \mathrm{g} / \mathrm{ml} ;$ P-value $<0.011$, student $\mathrm{t}$ - test) (Figure 6C). This indicates that overexpression of Arl1 provides protection against COS-induced cell permeability and damage.

\section{Yeast stress responses and COS-5.44 resistance}

Given our observation that the transcriptional changes in the overexpressing strains include genes involved in stress responses, we investigated whether these strains had activated well known stress responses that could potentially account for the strain's resistance to COS-5.44 treatment. To test this hypothesis, the wild type strain (BY4743) was exposed to a sub-lethal dose of different primary stresses previously reported by Berry and Gasch 2008, [38] followed by exposure to acute stress.

The wild type strain was first exposed to sub-lethal doses of stress (mild primary stress) followed by $2 \mathrm{~h}$ exposure to COS-5.44 (acute secondary stress). The primary mild stresses tested were: $0.25 \mathrm{M}$ and $0.5 \mathrm{M} \mathrm{NaCl}$, $1 \mathrm{M}$ sorbitol, $0.003 \%$ and $0.006 \% \mathrm{H}_{2} \mathrm{O}_{2}$ for $60 \mathrm{~min}, 37^{\circ} \mathrm{C}$ for $15 \mathrm{~min}$ and $30^{\circ} \mathrm{C}$ control (see Methods).

Wild type cells did not acquire resistance to COS-5.44 treatment after exposure to sub-lethal doses of different primary stressors (Additional file 1: Figure S11), although there was some variation in how the different primary stressors affected yeast growth when challenged with COS-5.44. In the $30^{\circ} \mathrm{C}$ control treatments, there was a similar amount of growth in both the control medium (0.5X YPD $\mathrm{pH} 5$ ) and vehicle (1\% DMSO); 

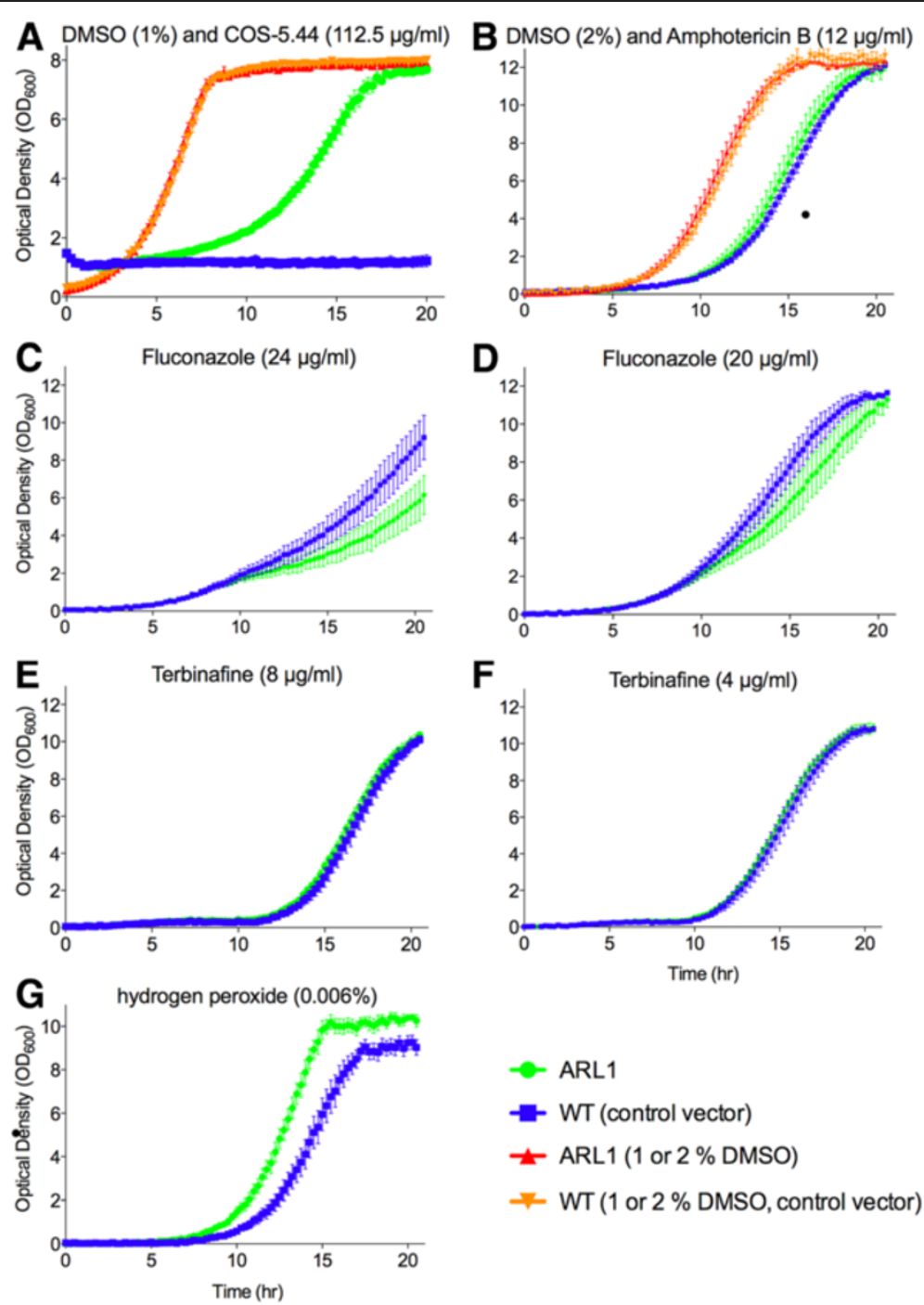

Figure 7 Effect of osmotic stressors, antifungal agents and oxidative stress on the growth of Arl1 overexpressing and wild type cells. A) Arl1 overexpression confers resistance to COS-5.44 at a concentration that inhibits growth of the vector control cells. The Arl1 overexpressing strain is as sensitive as the wild type cells to the tested antifungal compounds: B) Amphotericin B; C-D) Fluconazole; E-F) Terbinafine. Overexpression of $A R L 1$ confers tolerance to $\mathrm{H}_{2} \mathrm{O}_{2}(\mathbf{G})$ compared with the wild type. All assays were done in YPD except COS-5.44 that was done in 0.5X YPD. Optical density readings were taken every 15 min over 20 hrs using a Tecan Genios reader. Tecan ODs were converted to conventional $1 \mathrm{~mm}$ path length cuvette ODs using a calibration function provided by Ericson et al. 2010, [24]. Three colonies of each strain were grown in triplicate and compared with the wild type grown under the same conditions. YPD - Yeast Peptone Dextrose Broth.

however, when COS-5.44 treatment was applied, we observed growth inhibition (Additional file 1: Figure S11A). After stressing the wild type cells for $15 \mathrm{~min}$ at $37^{\circ} \mathrm{C}$, they could withstand $91.1 \mu \mathrm{g} / \mathrm{ml}$ of COS-5.44 and had a similar growth rate as wild type cells, but increasing COS concentrations dramatically inhibited growth rates (Additional file 1: Figure S11B). When the highest concentration of $\mathrm{NaCl}(0.5 \mathrm{M})$ was used as the primary stress, the effect of $112.5 \mu \mathrm{g} / \mathrm{ml}$ of COS-5.44 was increased, similar to what was observed when stressing cells for $15 \mathrm{~min}$ at $37^{\circ} \mathrm{C}$ (Additional file 1 : Figure S11C). The addition of $\mathrm{H}_{2} \mathrm{O}_{2}$ slowed growth of the wild type cells and $\mathrm{H}_{2} \mathrm{O}_{2}$ pre-treatment did not appear to provide resistance to COS-5.44 (Additional file 1: Figure S11E-F).

In contrast with the other stressors, sorbitol (1 M) stress decreased growth in both untreated and COS-5.44 challenged cells (Additional file 1: Figure S11D). It should be noted that sorbitol primary stress does appear to provide some protection against the higher concentrations of COS with cells growing as well in the higher as the lower concentrations of COS, a property not observed for the other stressors. The osmotic stress generated by sorbitol treatment is known to activate other 

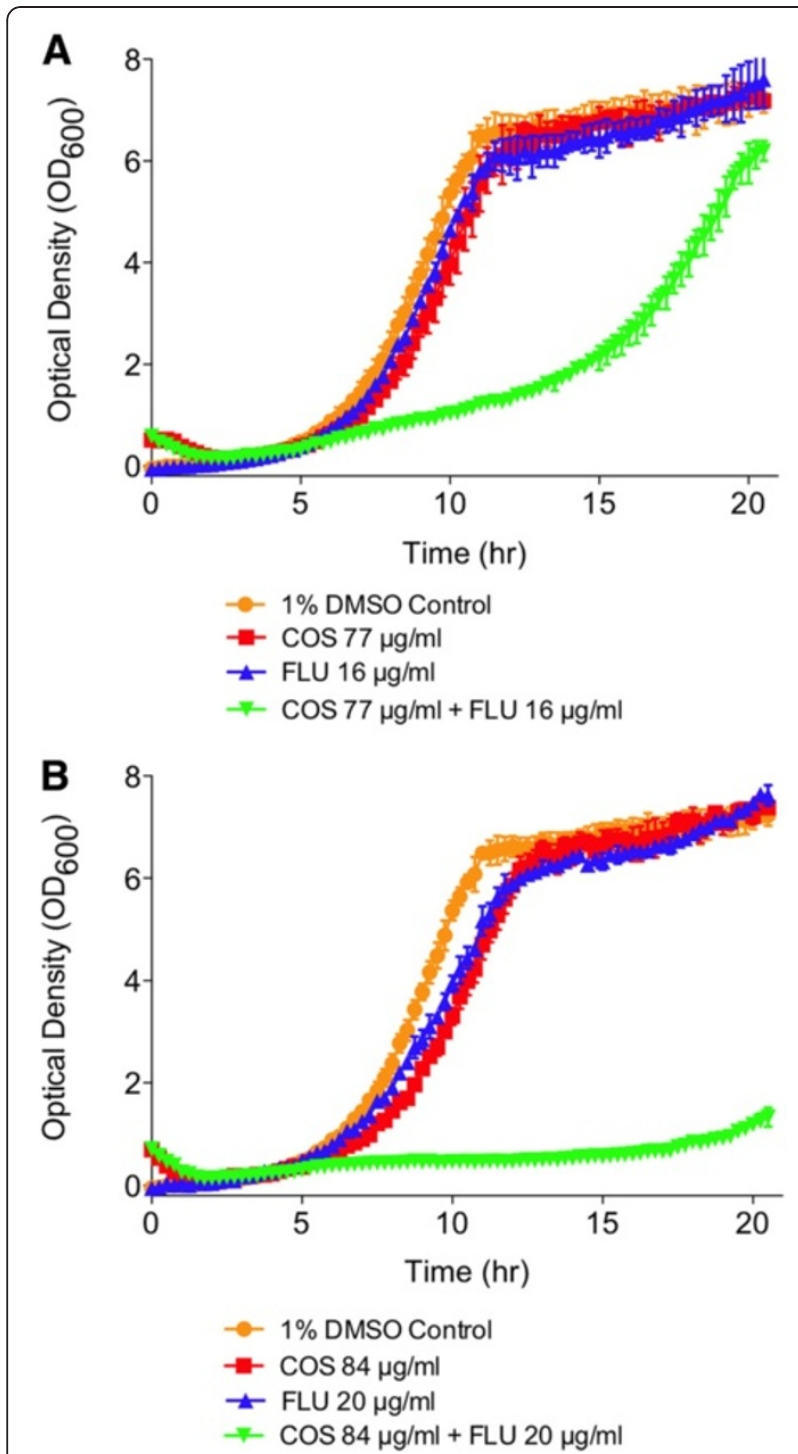

Figure 8 COS-5.44 has a synergetic inhibitory effect on cell growth when used in combination with Fluconazole. A) Growth curves of wild type strain (BY4743) growth in the vehicle, COS-5.44 $(77 \mu \mathrm{g} / \mathrm{ml})$, Fluconazole $(16 \mu \mathrm{g} / \mathrm{ml})$ and COS-5.44 + Fluconazole (77 $+16 \mu \mathrm{g} / \mathrm{ml}$, respectively). B) Growth curves of wild type strain (BY4743) growth in the vehicle, COS-5.44 $(84 \mu \mathrm{g} / \mathrm{ml})$, Fluconazole $(20 \mu \mathrm{g} / \mathrm{ml})$ and COS-5.44 + Fluconazole $(84+20 \mu \mathrm{g} / \mathrm{ml}$, respectively). Optical density readings were taken as described in Figure 3.

pathways such as MAPK and HOG cascades [39] and our results show that sorbitol pre-treatment provides some protection against COS (Additional file 1: Figure S11D)[39]. The sorbitol results are consistent with the findings of Zakrzewska et al. 2007, [23] who found that when HOG pathway mutants and wild type cells, were exposed to $1 \mathrm{M}$ sorbitol, partial protection against chitosan was observed. Overall, these results suggest that the COS-5.44 stress response is different from the previously described environmental stress responses and as a result, most pre-stresses do not confer resistance to COS.

\section{$A R L 1$ resistance to other antifungal compounds or stresses}

To test whether overexpression of $A R L 1$ confers resistance to other antifungal agents, cationic compounds, or osmotic stresses, wild type (vector control) and ARL1 overexpression strain cells were grown in the presence of these perturbations. Overexpression of $A R L 1$ did not confer resistance to $\mathrm{NaCl}$, sorbitol or $\mathrm{LiCl}$ compared with the vector control (data not shown). Overexpression of $A R L 1$ does confer resistance to COS-5.44 at high concentrations $(112.5 \mu \mathrm{g} / \mathrm{ml})$ where the vector control is unable to grow (Figure 7A). Interestingly, the ARL1 overexpression strain is as sensitive to Amphotericin B $(12 \mu \mathrm{g} / \mathrm{ml}$, Figure $7 \mathrm{~B}$ ) and Terbinafine (16 (not shown), 8 and $4 \mu \mathrm{g} / \mathrm{ml}$, Figure $7 \mathrm{E}$ and F) as the wild type cells. The ARL1 overexpression strain appears to be slightly more sensitive than the vector control to Fluconazole (32, 28, (not shown) 24 and $20 \mu \mathrm{g} / \mathrm{ml}$, Figures $7 \mathrm{C}$ and D). These results suggest that the resistance to COS resulting from $A R L 1$ overexpression is specific and does not extend to other antifungal compounds that disrupt fungal cell membranes [40]. Overexpression of ARL1 allows cells to withstand $\mathrm{H}_{2} \mathrm{O}_{2}$ perturbation slightly better $(12 \%)$ than control cells suggesting that $A R L 1$ overexpression may be providing some protection against oxidative stress (Figure 7G).

\section{Synergistic interaction of COS-5.44 with fluconazole}

Because COS-5.44 and Fluconazole have different modes of action, we examined the effect of treating cells with both compounds simultaneously to test if these two compounds might interact synergistically. We quantified the degree of interaction across different concentrations in a dose response matrix for each drug interacting with itself and with the other drug (Additional file 2: Table S8 - S11). At concentrations where either drug only weakly inhibits cells growth (i.e. COS inhibits growth $\leq 15 \%$ while Fluconazole inhibits $\leq 9 \%$ ) when used in combination, a dramatic decrease in cell growth is observed (Figure 8A,B). Using the area under the growth curve as a metric, the combination of COS-5.44 and Fluconazole act in a synergistic fashion since the combination of both drugs inhibits growth much more (i.e. 45 to $86 \%$ inhibition) than the sum of growth inhibition caused by each compound individually.

\section{Discussion}

We have applied multiple comprehensive chemogenomics assays in yeast to identify the gene targets of COS-5.44. Unlike other antifungal drugs tested with the same approach [24] where typically 3-10 genes are identified as potential drug targets, we found a much larger gene set (39) of yeast deletion strains highly sensitive to COS-5.44. The most sensitive heterozygous deletion 
strain in the pool will often be the drug target $[24,26]$. In our case, we identified 17 heterozygous deletion strains, suggesting that $\operatorname{COS}$ does not target a single specific protein as its antifungal mode of action. In a previous global fitness assay similar to the HIP-HOP assay, 101 homozygous strains were sensitive after $9 \mathrm{~h}(\sim 6-7$ generations) of exposure to $25 \mu \mathrm{g} / \mathrm{ml}$ of $10 \mathrm{kDa}$ chitosan. Very few heterozygous strains were identified as sensitive to chitosan [23]. The differences seen in our results compared to those of Zakrzewska et al. [23] are likely due to a number of different experimental parameters. First, there were differences in the form and concentration of COS used, (i.e. a lower concentration and larger molecular weight of COS was used in that study [23]).
As we described earlier, the physiochemical properties of $\mathrm{COS}$ such as degree of deacetylation and molecular weight are known to affect COS's biological activity $[16,41,42]$. Second, the treatment period used in the Zakrzewska et al. study was shorter than in the one used in our study ( 9 vs. 40 hrs equivalent to $\sim 6-7$ and 20 generations respectively). The shorter exposure time could explain the low number of chitosan sensitive heterozygous deletion strains found by these authors since the subtle phenotypes of the heterozygous deletions strains often require longer growth periods to resolve fitness differences between strains [43]. Finally, the lower threshold for the identification of sensitive strains (i.e. those having a $\log 2$ ratio of $\geq 1.585$ ) used by

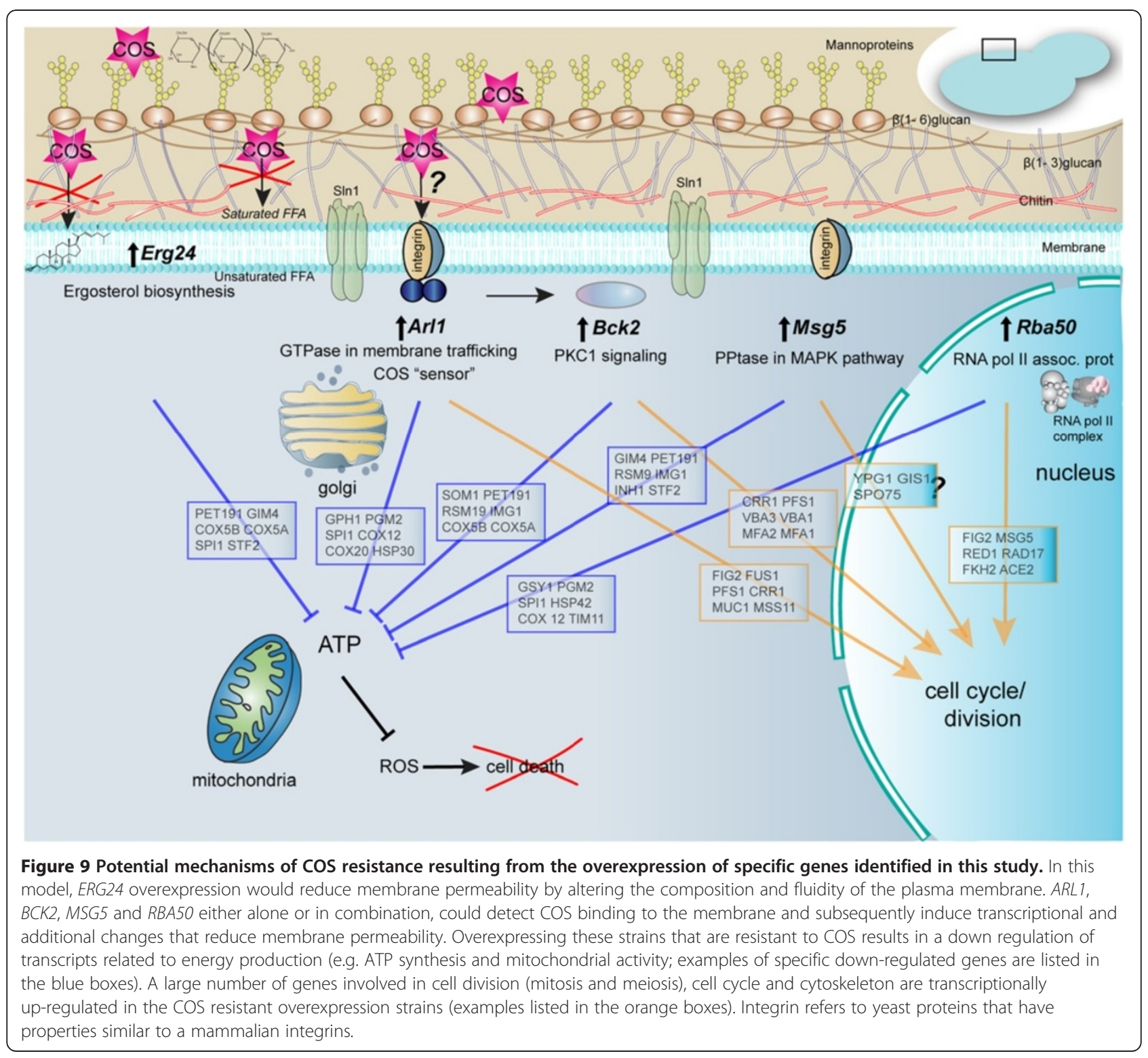


Zakrzewska et al. 2007, [23] accounts for the higher number of homozygous strains they determined to be chitosan sensitive.

Several of the genes sensitive to COS in our HIP-HOP assay and resistant in the multicopy suppression assay were enriched for proteins targeted to membranes. This is not surprising given that COS likely perturbs membrane integrity. COS might also be creating oxidative stress leading to the accumulation of damaged proteins that are degraded by the proteosome. Protein degradation/proteosome functions were among the biological processes enriched in the HIP-HOP assays (Figure 2C).

We selected 5 of the confirmed overexpressing strains that provide resistance to $\mathrm{COS}$ to uncover any changes in their gene expression profiles that might give insights into COS's mechanism of action. ARL1 (YBR164C) was found to be sensitive to COS as a deletion strain in the HOP assay and resistant in the MSP assay in this study and was found to be sensitive to chitosan as a homozygous deletion strain in a previous study [23]. We confirmed that an $A R L 1$ deletion strain was sensitive to COS-5.44 and overexpression of $A R L 1$ conferred resistance to COS-5.44 (Figures $3 \mathrm{~B}$ and $3 \mathrm{D}$ ). We believe the identification of this gene does provide information into the molecular mechanism of COS-5.44. Arl1 is a G protein and soluble GTPase and is a member of the Ras superfamily [28,44]. Arl1 is highly conserved in all eukaryotes with $65 \%$ homology to human ADPribosylation factor-like protein 1 (Arl1). Arl1 has been shown to be associated with the trans-Golgi and is thought to be required for endosome-Golgi trafficking [45,46]. Arl1-GTP recruits specific receptor proteins to the membrane surface by binding to their GRIP domains, although in yeast, no specific Arl1 binding receptor proteins have yet been identified $[44,45]$. Mutations in yeast $A R L 1$ are not lethal [28] but $A R L 1$ mutants do show mild defects in localizing proteins to vacuoles as well as defects in potassium uptake [44,46-48]. arl1 mutants have also been shown to be more sensitive to antifungal agents such as Hygromycin B [46]. Arl1 can be myristolayted and we hypothesize that through myristoylation, the soluble form of the GTPase could be bound to the membrane bilayer. In this way $A R L 1$ could act as a sensor and modulate membrane trafficking at the onset of COS 5.44 induced membrane permeabilization (Figure 9). Arl1 (Arl1p, PDB id 1moz) has been predicted to weakly associate with membranes (deltaG of $-4 \mathrm{kcal} / \mathrm{mol}$ without ligands for the dimer) with the $\mathrm{N}$-terminal residues $(\mathrm{N}$ myristoyl glycine) of each dimer binding to the membrane $[27,49,50]$. GTPases are known to be involved in signal transduction pathways in filamentous fungi and yeast. These proteins are also involved in conidiation, a process that is enhanced by chitosan treatment in filamentous fungi [8]. When the $A R L 1$ gene is overexpressed and yeast cells are challenged with COS, a large set of genes related to cytoskeleton organisation (e.g. microtubule dynamics) and stress sensing are up-regulated (Figure 5). These genes are also involved in cell division (mitosis and meiosis) and the cell cycle. This could explain the ability of chitosan to enhance sporulation $[28,44]$.

ERG24, which encodes C-14 sterol reductase, is a gene involved in ergosterol biosynthesis. Because ergosterol is a unique lipid in fungal membranes it is a classical target of many antifungal compounds. In a previous study, while ergosterol content was not associated with resistance to chitosan, in some filamentous fungi saturation of free fatty acids was associated with resistance [51]. Free fatty acid desaturases lower membrane fluidity and desaturase mutants have been found to confer resistance to chitosan in N. crassa [51]. Membrane patches rich in ergosterol and other lipids alter membrane fluidity and are important for correct membrane function [52]. It also has been shown that an increase in sterol biosynthetic capacity results in an increase in the availability of fatty acids [53]. We can envision that overexpression of ERG24, a key gene in the ergosterol biosynthetic pathway, could increase the size/presence of ergosterol rich membrane rafts and fatty acid content making the membrane less fluid and therefore more resistant to COS.

For both yeast and filamentous fungi, the plasma membrane is the primary target for chitosan. In yeast, chitosan causes cell leakage and stops cell growth [22]. In filamentous fungi, chitosan permeabilizes the membrane in an energy dependent manner and kills cells of sensitive species such as $N$. crassa conidia [54]. A recent study by Palma-Guerrero et al. 2010, [51] found that membrane fluidity is a key factor in the antifungal action of chitosan with fluid fungal membranes binding more chitosan than less fluid ones. Chitosan crosses the fungal cell wall and binds to membrane lipids with a preference for negatively charged ones [51]. Chitosan permeabilizes the membrane when the concentration reaches a critical level $[55,56]$. Our study identifies pathways involved in membrane structure and signalling that are affected by COS. The Sytox uptake experiments confirm that membrane permeability is increased when cells are exposed to COS and that overexpression of $A R L 1$ suppresses the increase in membrane permeability caused by COS (Figure 6).

While our work and previous studies have shown that chitosan induces stress responses in yeast and other fungi, our study shows that pre-treatment with any of the well characterized environmental stresses (thermal, salt, osmotic and oxidative) does not provide resistance to COS-5.44 in yeast (Additional file 1: Figure S11). Therefore, the changes induced by COS would appear to be different from previously described environmental stress response pathways. 
Assuming that COS's main mode of anti-fungal action is to increase the permeabilization of membranes, we speculate that several of the genes we have identified in this study are involved in a cellular response that reduces permeabilization of the membrane and/or mitigates the damage induced by the permeabilization. For example, ARL1, BCK2 and MSG5 could be part of a sensing and signalling mechanism(s) that detects COS binding to the membrane that induces transcriptional and other changes to reduce membrane permeability. ERG24 could be reducing membrane permeability by affecting the composition and fluidity of the membrane (Figure 9). Ultimately, if COS concentrations are too high, the cellular response would be insufficient to prevent membrane permeabilization and cell death would ensue - possibly as a result of the release/leakage of oxygen radicals from the mitochondria. While the exact mechanism of cell death by COS is still unknown, it appears to be a respiration/ATP-dependent process in filamentous fungi [54]. Overexpressing strains resistant to COS display down-regulated genes related to energy dependent processes (ATP synthesis, mitochondrial activity, etc.) (Figure 5; Additional file 1: Figures S5-S9; Additional file 2: Table S6). In this sense, the overexpressing strains would mimic the effect of treatments such as sodium azide and low temperature that inhibit oxidative respiration and chitosan damage to fungal cells [54]. Interestingly, the $A R L 1$ overexpression strain also shows increased resistance to certain forms of oxidative stress such as $\mathrm{H}_{2} \mathrm{O}_{2}$ (Figure 7G). The transcriptome analysis of several of the overexpressing strains suggests that resistance to COS involves generation of less ROS by reducing oxidative respiration as well as reducing cell responses to ROS.

A comparison of the gene targets found in the HIPHOP screens in this study to genes found in similar screens for other fungicides that act at the cell membrane (e.g. Amphotericin B, Fluconazole and Terbinafine) suggests that COS may have a different mechanism of action than these other drugs [57]. In support of this hypothesis, we have found that the $A R L 1$ overexpression strain does not provide resistance against Amphotericin B, Fluconazole or Terbinafine (Figure 7B-F). This suggests that COS might be an effective antifungal agent in strains that are resistant to the other perturbing cell membrane compounds.

Fluconazole, Terbinafine and Amphotericin B antifungal activity involves the targeting of ergosterol, the principal cell membrane sterol of fungi, by different mechanisms. Fluconazole (an triazole) inhibits $14 \alpha-$ demethylase (lanosterol demethylase, Erg11), a fungal cytochrome P450 dependent enzyme, and depletes cell membrane ergosterol resulting in reduced membrane fluidity, and the accumulation of $14 \alpha$-demethylated sterols that are toxic to the cell. This leads to growth arrest and eventual fungal cell death $[58,59]$. Terbinafine inhibits squalene monoxygenase (Erg1), an enzyme responsible for conversion of squalene epoxide, a precursor to lanosterol in the ergosterol synthesis pathway [59]. Amphotericin B targets the fungal cell membrane by directly binding to ergosterol, forming complexes that intercalate the cell membrane, resulting in formation of pores and leakage of intracellular contents [60,61]. COS appears to perturb the cell membrane possibly through the ergosterol pathway, by targeting ERG24, a gene that encodes for C-14 sterol reductase [62].

Because COS seems to have a distinct mode of action compared with other antifungals, we were interested in seeing its inhibitory effect when used in conjunction with another antifungal drug. We tested COS and Fluconazole in combination (as well as on their own), and saw a strong synergism between them. That is, at concentrations where either drug alone had little inhibitory effect, a strong inhibitory effect that was much greater than additive was observed when they were combined (45 to $86 \%$ growth inhibition; Figure $8 \mathrm{~A}, \mathrm{~B})$. One possible explanation for this synergy might be that the increased membrane permeability induced by COS allows more Fluconazole to penetrate the cell membrane to inhibit $14 \alpha$-demethylase that in turn further reduces membrane fluidity and increases the production of toxic sterols.

\section{Conclusions}

The results of this study have provided insights into the molecular mechanisms of the antifungal modes of action of COS. Some of the pathways COS appears to affect include sensing, signalling, and the composition of the cell membrane (Figure 9). Our results suggest that COS does not have a single specific gene target. We provide evidence that COS increases cell membrane permeability and that the overexpression of $A R L 1$ can reduce the permeability induced by COS. Resistance to COS does not confer resistance to other antifungal compounds that disrupt the fungal cell membrane such as azoles, polyenes and Terbinafine. COS can synergize with other antifungal agents such as Fluconazole suggesting that COS could be considered as alternative antifungal treatment to fungal pathogens that are resistant to other antifungal compounds or be used in combination with other antifungal agents to enhance their activity.

\section{Methods}

\section{Chitosan oligosaccharide}

Chitosan oligosaccharide (COS-5.44) (5.44 KDa, PDI (poly dispersity index $)=1.14$ and $97 \%$ degree of deacetylation) was kindly provided by Dr V. Tikhonov (Laboratory of Physiologically Active Biopolymers, A. N. Nesmeyanov 
Institute of Organoelement Compounds, Russian Academy of Sciences, Moscow, Russia). COS-5.44 was prepared as described by Tikhonov et al. 2006, [20]. For the experiments performed in this study, a COS-5.44 stock solution $(25 \mathrm{mg} / \mathrm{ml})$ in $50 \%$ DMSO was prepared, aliquoted and stored at $-20^{\circ} \mathrm{C}$.

\section{Chitosan}

Chitosan (T8s) with a molecular weight of $70 \mathrm{kDa}$ and $80 \%$ degree of deacetylation was obtained from Marine BioProducts GmbH (Bremerhaven, Germany). Chitosan was prepared as described by Palma-Guerrero et al. 2008, [55]. Each batch of dialyzed and autoclaved chitosan was stored at $4^{\circ} \mathrm{C}$ for a maximum of 2 weeks.

\section{Yeast sensitivity to COS-5.44 and chitosan}

A pre-screen of COS-5.44 and chitosan (T8s) in wild type yeast (BY4743) was performed as described in Pierce et al. 2007, [43] to determine the antifungal activities of these two compounds that have different molecular weights and degrees of deacetylation. For the pre-screen of COS-5.44, concentrations from $62 \mu \mathrm{g} / \mathrm{ml}$ to $125 \mu \mathrm{g} / \mathrm{ml}$ of COS-5.44 were tested (Figure 2B). $98 \mu \mathrm{l}$ of cell mix at an initial $\mathrm{OD}_{600}$ of 0.0625 in $0.5 \mathrm{X}$ YPD pH 5 (5 g bacto yeast extract, 10 bacto peptone and $10 \mathrm{~g}$ dextrose in $1 \mathrm{l}$ distilled water [63]) was added to each well of a 96 well plate (Nunc) then $2 \mu \mathrm{l}$ of the corresponding COS-5.44 stock were added, including carrier controls (50\% DMSO and $0.25 \mathrm{~mol} / \mathrm{l} \mathrm{HCl}$ neutralized $\mathrm{pH} 5.6)$. The chitosan (T8s) screen followed the same protocol, with the slight difference in volume of cell mix $(97 \mu \mathrm{l})$ added and chitosan (T8s) stock (3 $\mu \mathrm{l})$. Concentrations from $125 \mu \mathrm{g} / \mathrm{ml}$ to $162.5 \mu \mathrm{g} / \mathrm{ml}$ of chitosan (T8s) were tested (Additional file 1: Figure S1) Cells were grown at $30^{\circ} \mathrm{C}$ in a shaking-spectrophotometer (Tecan), with readings taken every $15 \mathrm{~min}$ for $24 \mathrm{hrs}$. Tecan ODs were converted to conventional $1 \mathrm{~mm}$ path length cuvette ODs using a calibration function provided by Ericson et al. 2010, [24]. The COS-5.44 pre-screen was performed to identify an $\mathrm{IC}_{70-90}$ and $\mathrm{IC}_{10-20}$ of COS-5.44 in the BY4743 to be used in the multicopy suppression and deletion profiling (HIP-HOP) respectively (Figure 2B).

\section{Haploinsufficiency and homozygous profiling (HIP-HOP) assay}

Haploinsufficiency and Homozygous profile assays, genomic DNA purification, PCR amplification of barcodes, array hybridization, analysis and confirmation were performed as described in Ericson et al. 2010, [24]. The homozygous collection was grown for 5 generations (approximately $10 \mathrm{hrs}$ ) and the heterozygous collection for 20 generations (approximately $40 \mathrm{hrs}$ ), as these periods of time have been found to be optimal to allow each collection to resolve growth differences [43].

Experiments were performed in duplicate. Yeast deletion strains with $\log 2$ ratio of 3.5 or higher (Highly sensitive COS-5.44 deletion strains) were selected for individual confirmation. A $\log 2$ ratio of 3.5 represents an approximately 11 - fold less abundance of the deletion strain after COS treatment.

\section{Multicopy suppression profiling and screen conditions}

MSP screen, plasmid isolation, Affymetrix TAG4 array hybridization, microarray results analysis and confirmation followed the protocols described by Hoon et al. 2008, [25] and Ericson et al. 2010, [24].

\section{Transformation of candidate resistant genes for overexpression in yeast}

Sixty-eight genes were identified with MSP as possible candidates to confer resistance to COS-5.44 (Additional file 1: Figure S2). To confirm which of the 68 genes conferred resistance, each gene was individually overexpressed in yeast. For this purpose E. coli strains carrying the genes of interest were obtained from the MoBY-ORF $2 \mu$ collection, kindly provided by Sarah Barker from the Boone lab [30]. 57 of the 68 candidate genes were available in the MoBY-ORF $2 \mu$ collection and thus 11 of the genes of interest were not present in this collection and could not be tested.

Individual colonies of each $E$. coli strain were grown in selective media in 2YT (1\% Yeast extract, $1.6 \%$ Bacto tryptone, and $0.5 \%$ Sodium $)+0.4 \%$ Glucose + Carbenicillin (200 mg/ml, SIGMA) + Kanamycin (50 mg/ml, SIGMA) in 96 square well blocks (Greiner, Bio-one) at $37^{\circ} \mathrm{C}$ and 200-250 rpm. Cells were harvested (5 min, $4000 \mathrm{rpm}$ ) to proceed with DNA extraction. MachereyNagel Multi-96 purification kit (MN Cat \# 740 625.4) was used to miniprep the plasmids, following the manufacturer's protocol. Elution was done in $150 \mu \mathrm{l}$ to collect $\sim 100 \mu \mathrm{l}$ of purified DNA.

Each plasmid extract was double digested with EcoRI/ XhoI (New England BioLabs Inc.). Digested samples were run on a $0.8 \%$ agarose gel to confirm vector and ORF fragments size.

The confirmed plasmids were transformed into yeast strain BY4743 (his3 1/his3 1 leu2 0/leu2 0 ura3 0/ura3 0 met15 0/+ lys $20 /+$ ), using a 96 well yeast transformation protocol as described by Gietz et al. 2007, [64]. Five single colonies of each strain were grown overnight in selective liquid media then archived in $15 \%$ glycerol at $-80^{\circ} \mathrm{C}$.

Once overexpressing strains were obtained, confirmation of resistance to COS-5.44 was performed (Figure 1). Overexpressing strains were grown at different concentrations of COS-5.44 previously found to be 
inhibitory to the wild type strain in MSP. Concentrations tested were 101.25, 106.28, 112.5, 118.75, 125.0 and $250.0 \mu \mathrm{g} / \mathrm{ml}$. To ensure that the resistance was conferred by the overexpressed gene, plasmid DNA was extracted from two colonies of each overexpressing strains, and transformed into E. coli. Amplified plasmids were extracted using Genejet kit (Fermentas) following manufacturer protocol. Purified plasmids were double digested as described. Confirmed plasmids were retransformed into BY4743 and three single colonies were selected and confirmed for COS-5.44 resistance as previously described.

\section{Sample collection and RNA extraction of overexpressing strains}

A confirmed colony of each overexpressing strain and the wild type with the empty vector was grown overnight at $30^{\circ} \mathrm{C}$ and shaking at 200-250 rpm. An overnight culture was used to inoculate 3 flasks each with $400 \mathrm{ml}$ of 0.5X YPD pH 5. Cells were grown until the culture reached an $\mathrm{OD}_{600}$ of 0.8 and a $100 \mathrm{ml}$ sample was collected (time zero). The remaining $300 \mathrm{ml}$ were treated with COS-5.44 $(112.5 \mu \mathrm{g} / \mathrm{ml})$ and $100 \mathrm{ml}$ samples were collected at 15, 30 and 60 min after treatment (Figure 1). Cells were collected by centrifugation ( $5 \mathrm{~min}, 4000 \mathrm{rpm}$ ) frozen with liquid nitrogen and stored at $-80^{\circ} \mathrm{C}$, for RNA extraction and labeling. Once all samples were collected a hot acid phenol-chloroform RNA extraction was performed [65].

Microarray analysis (see below) of the COS treated wild type cells found that the maximum number of differentially expressed genes were obtained with the 60 min treatment with minimal loss of genes differentially expressed at earlier time points but not at $60 \mathrm{~min}$. Therefore, for the overexpression strains, microarray analysis was only performed on the untreated and 60 min COS treated samples.

\section{cDNA and microarray sample preparation}

cDNA synthesis and sample labeling for NimbleGen $4 X 72 \mathrm{k}$ yeast microarrays (Roche NimbleGen, Inc.; Design ID A6186-00-01, TI4932 60mer expr X4) was performed as described in the manufacturer's protocol with minor modifications. cDNA synthesis was performed using $10 \mu \mathrm{g}$ of total RNA. The sample labeling reactions were done using $1 \mu \mathrm{g}$ of double stranded cDNA. Three cDNA biological replicates either with or without a 60 min exposure to COS-5.44 for each of the 5 overexpressing strains as well as an untransformed wild type BY4743 cells (vector control; for a total of 36 samples) were hybridized to NimbleGen $4 X 72 \mathrm{k}$ microarrays (Roche NimbleGen, Inc.). Microarrays were scanned with a Genepix 4000B scanner (Molecular Devices Inc. Sunnyvale, CA).

\section{Microarray data analysis}

Raw images were obtained using GenePix Pro software (Version 5.0, Molecular Devices Inc. Sunnyvale, CA). Raw probe intensities ( $\mathrm{x}, \mathrm{y}$ and signal reports) were obtained using NimbleScan software (v2.4, Roche NimbleGen, Inc). Data preprocessing of 60mer oligonucleotide arrays was performed using the BioConductor package Oligo [66]. Genes with significant expression difference compared with the vector control (wild type, BY4743) were identified for each overexpressing strain using the BioConductor package Limma Linear models for microarray analysis, [67], taking P-value $\leq 0.05$ and $\log 2$ fold change of $\geq 1$ or $\leq \_1$ as significant unless otherwise noted. The data discussed in this publication have been deposited in NCBI's Gene Expression Omnibus [68] and are accessible through GEO Series accession number GSE32888 (http://www. ncbi.nlm.nih.gov/geo/query/acc.cgi?acc=GSE32888).

\section{Hierarchical clustering}

Hierarchical clustering of the data was performed using the program Cluster 3.0 originally written by Eisen, [69], modified by de Hoon, [70]. Expression data of the 5 overexpressing strains was clustered using city-block distance measurement and average linkage clustering method. The resulting clusters were visualized using Java TreeView [71].

\section{Functional annotation of chemogenomic assays and microarray results}

The genome-wide profile of the COS-5.44 sensitive deletion strains was examined using Gene Set Enrichment Analysis GSEA, [29] to identify enriched biological processes. GSEA has been considered advantageous for quantitative genome-wide profiles because it can take into account the entire profile, exploiting the weighting of the genes (e.g. degree of sensitivity to a drug (i.e. fitness defect), differential gene expression). Other functional analysis methods focus on a list of genes that satisfy the characteristic of interest. This would first require setting a threshold to divide the profile into lists of genes that satisfy the characteristic of interest and those that do not. It is often unclear how to choose an appropriate threshold, yet with GSEA, choosing such a threshold is not required.

Deletion strains were mapped to genes using chromosomal feature data downloaded from the Saccharomyces Genome Database (SGD) on April 16, 2011. Multidrug resistance genes MDR, [57] were filtered from the genome-wide profile of sensitive deletions strains to COS, to identify biological process specific to COS response. The list of all genes ranked by their fitness defects was analyzed by GSEA v2.07 (4864 genes, without MDR genes) [29]. Default parameters were used except that minimum and maximum gene set size were 
restricted to 5 and 300, respectively. Biological process annotation was obtained from Gene Ontology website (http://berkeleybop.org/goose) on April 13, 2011. Additional protein complex annotations based on consensus across different studies were obtained from Benschop et al. 2010, [72].

Enrichment maps were generated with Enrichment Map Plugin v1.1 [73] developed for Cytoscape [74] with default parameters. Nodes in the maps were clustered with the Markov clustering algorithm, using an overlap coefficient computed by the plugin as the similarity metric (coefficient $<0.5$ were set to zero) and an inflation parameter with value of 2 . For each cluster leading edge were computed as in Subramanian et al. 2005, [29] for each member of a node. The top 10 leading edge genes associated with the most nodes in the cluster are shown in the bar plot (if less than 10 genes, all are shown).

A functional analysis (i.e. GSEA [29]) was performed as described above for the transcriptional profiles of the wild type (BY4743) exposed to COS-5.44 and the $60 \mathrm{~min}$ chitosan data set from Zakrzewska et al. 2005, [22] that was performed on X2180-1A, MATa SUC2 mal gal2 CUP cells. The set of environmental stress response genes ESR, [75], were filtered from the transcriptome data sets to identify the biological processes enriched by COS or chitosan treatment apart of the general stress response of yeast. Enrichment maps were generated with Enrichment Map Plugin v1.1 [73] developed for Cytoscape [74] with the following parameters: FDR $<1 \%$, p-value $<0.005$ and using an overlap coefficient computed by the plugin as the similarity metric (coefficient $<0.5$ were set to zero). Enrichment maps were compared with the comparison function of the Enrichment Map Plugin v1.1 [73].

A similar functional analysis was performed on the whole transcriptome dataset of each overexpressing strain. As was described above, the set of environmental stress response genes were filtered from the transcriptome data set. An additional enrichment analysis of significantly upor down-regulated transcripts (P-value $\geq 0.05$ and $\log 2$ fold changes $\geq 1$ or $\leq \_1$ ) was also performed using the single enrichment analysis tool of Babelomics [35,36]. All default parameters were used.

\section{Quantitative RT-PCR}

Quantitative reverse transcription - PCR (qRT-PCR) verification of the microarray results for selected genes, was performed using KAPA SYBR FAST (KAPA Biosystems) in a CFX384 real-time PCR detection system (Bio-Rad), with two biological replicates from wild type (vector control BY4743) or Arl1 overexpressing strain that were either untreated or exposed to COS-5.44 for 60 min. Each RT qPCR reaction had 200 pg of cDNA, 5 $\mu \mathrm{L}$ of KAPA SYBR FAST master mix (2x), $300 \mu \mathrm{M}$ of each primer and water to have a final volume of $10 \mu \mathrm{L}$ per reaction. Cycling conditions used were as follows: $95^{\circ} \mathrm{C}$ for $3 \mathrm{~min}$, followed by 40 cycles of $95^{\circ} \mathrm{C}$ for $3 \mathrm{~s}$ and $60^{\circ} \mathrm{C}$ for $30 \mathrm{~s}$ then $95^{\circ} \mathrm{C}$ for $10 \mathrm{~s}$. All the reactions were performed in triplicate, using primers for the following genes: ACT1, ARL1, CMD1, COX5B, ERV25, FIG2, HSP30, MUC1, RCR1, RPL32, SPT15, UBI4 and VBA5. Primers were designed using Primer-BLAST Developed at NCBI uses Primer 3, [76]. See Additional file 2: Table S6 for the sequences of the primers used. The average of three technical replicates was normalized to four internal control transcripts, ACT1, ERV25, RPL32, SPT15, there were not significant differences among internal controls therefore all were used for normalization. Data was analyzed using CFX Manager (Bio-Rad laboratories, Inc).

\section{Cell permeability assay}

Plasma membrane permeability was measured by SYTOX Green uptake as described by Thevissen et al. 1999, [37] with modifications. S. cerevisiae cells of the wild type and overexpressing strain $A r l 1$ were grown in the presence of COS-5.44 (91.1, 101.25, 106.28 and $112.5 \mathrm{mg} / \mathrm{ml}$ ) and vehicle control (1\% DMSO). Cultures of the overexpressing strain Arl1 and wild type (B4743) with empty vector were set up at initial OD of 0.0625 and grown overnight (17 hrs). After COS-5.44 treatment the cells were pelleted by centrifugation $(5 \mathrm{~min}$, $4000 \mathrm{rpm}$ ) and washed three times in $0.1 \mathrm{M}$ Tris $-\mathrm{HCl}$, $\mathrm{pH}$ 7.0. Two hundred microlitre aliquots of the yeast cell suspension was incubated with $0.2 \mu \mathrm{M}$ SYTOX Green in 96-well microplates for $30 \mathrm{~min}$ at $30^{\circ} \mathrm{C}$ with periodic agitation in the dark. Three replicates of each strain were performed. Fluorescence was measured using a Guava easyCyte flow cytometer (Millipore). The green fluorescence filter set $488 \mathrm{~nm}$ (excitation) and $520 \mathrm{~nm}$, (emission) was used. Fluorescence data was analyzed with the software FlowJo (V9.3.1, Tree Star, Inc.).

\section{Stress response and COS-5.44 resistance}

To verify if the activation of the environmental stress response (ESR) provides resistance to COS-5.44 treatment, the wild type strain (BY4743) was exposed to sub-lethal doses of primary stresses previously reported by Berry and Gasch 2008, [38] to provide resistance to more severe stresses. The yeast wild type strain was exposed to sub-lethal doses of stress (mild primary stress) then cells were exposed to chitosan oligosaccharide treatment (severe secondary stress). The primary mild stresses tested were: $0.25 \mathrm{M}$ and $0.5 \mathrm{M} \mathrm{NaCl}, 1 \mathrm{M}$ sorbitol, $0.003 \%$ and $0.006 \% \mathrm{H}_{2} \mathrm{O}_{2}$ for $60 \mathrm{~min}, 37^{\circ} \mathrm{C}$ for $15 \mathrm{~min}$ and $30^{\circ} \mathrm{C}$ control. Yeast cells were collected by centrifugation $(5 \mathrm{~min}$, $4000 \mathrm{rpm})$ then exposed to the secondary stress treatment COS-5.44 for two hours (91.1, 101.25, 0.1068 and $112.5 \mu \mathrm{g} / \mathrm{ml})$. After the secondary stress, cells were 
collected by centrifugation, transferred to YPD and their growth rates measured.

\section{Resistance to other antifungal and cationic compounds} To ask if the overexpression of ARL1 conferred resistance to other cationic compounds, the wild type and ARL1 overexpression strain were grown in the presence of other cationic compounds (as described in section 3.2).

A dose response assay was performed in the wild type and overexpression strain ARL1, as previously described screen protocol, using the following compounds: $\mathrm{NaCl}$ $(0.5$ and $1 \mathrm{M})$; sorbitol $(1$ and $2 \mathrm{M}) ; \mathrm{LiCl}(0.01 \mathrm{M})$; hygromycin B $(25,12$, and $6 \mu \mathrm{g} / \mathrm{ml}) ;$ Amphotericin B $(25,12$ and $6 \mu \mathrm{g} / \mathrm{ml})$; Fluconazole $(32,28,24$ and $20 \mu \mathrm{g} /$ $\mathrm{ml})$; Terbinafine $(16,8$ and $4 \mu \mathrm{g} / \mathrm{ml}) ; \mathrm{H}_{2} \mathrm{O}_{2}(0.012 \%$ $0.006 \%) ; 1 \% \operatorname{SDS}(0.05,0.025$ and $0.012 \%)$.

\section{Interaction between $\operatorname{COS}$ and fluconazole}

For COS-5.44, a concentration range of $35-105 \mu \mathrm{g} / \mathrm{ml}$ and for Fluconazole, a concentration range $4-24 \mu \mathrm{g} / \mathrm{ml}$ was used. Stocks for each drug treatment were prepared in $12.5 \%$ DMSO resulting in a final concentration of $1 \%$ DMSO. Wild type yeast (BY4743) was grown overnight and diluted at an initial $\mathrm{OD}_{600}$ of 0.0625 in $0.54 \mathrm{X}$ YPD $\mathrm{pH} 5.92 \mu \mathrm{l}$ of cell mix was aliquoted to each well of a 96 well plate (Nunc), and $4 \mu \mathrm{l}$ of the corresponding COS-5.44 and/or Fluconazole stock were added in a $7 \times 12$ dose response matrix. Two dose response matrices were performed: self-self (COS-5.44 - COS-5.44 and Fluconazole - Fluconazole) and two replicates of the COS-5.44 and Fluconazole matrix. Cells were grown at $30^{\circ} \mathrm{C}$ in a shaking-spectrophotometer (Tecan), with readings taken every $15 \mathrm{~min}$ for $24 \mathrm{hrs}$. We used the area under the growth curve as a metric to measure growth inhibition and drug interaction.

\section{Additional files}

Additional file 1: Figures S1 - S11 and their corresponding figure legends.

Additional file 2: Tables S1 - S13 and their corresponding legends.

\footnotetext{
Abbreviations

COS: Chitosan oligosaccharide or chitooligosaccharide; DMSO: Dimethyl sulfoxide; ESR: Environmental stress response; FDR: False discovery rate; FLU: Fluconazole; GEO: Gene expression omnibus; GSEA: Gen set enrichment analysis; HIP: Haploinsufficiency profiling; HOG: High osmolarity glycerol; HOP: Homozygous profiling; IC: Inhibitory concentration; Limma: Linear models for microarray analysis; MAPK: Mitogen-activated protein kinase; MDR: Multidrug resistance genes; MoBY-ORF: Molecular barcoded yeast ORF library; MSP: Multicopy suppression profile; PDI: Poly dispersity index; qRT-PCR: Quantitative reverse transcription - PCR; Ras superfamily: Rat sarcoma superfamily; ROS: Reactive oxygen species; SGD: Saccharomyces genome database; YPD: Yeast peptone dextrose; YT: Yeast triptone.
}

Competing interests

The authors declare that they have no competing interests.

\section{Authors' contributions}

MDLAJ, LVLL, JTW and CN conceived, designed the experiments and wrote the manuscript. GG provided the chemogenomic assay platform and reagents. MDLAJ and MG performed chemogenomic assays. MDLAJ carried out the overexpression strains study. MDLAJ, AYL and LEH performed chemogenomics data analysis and enrichment maps. MDLAJ and MP performed analysis of yeast strains growth confirmations. MDLAJ and AC carried out the transcriptional analysis. AC, MP, LEH provided advice in data analysis. Experimental work was carried out in the labs of GG, JTW, CN and the Canadian Drosophila Microarray Center (CDMC). All authors read and approved the final manuscript.

\section{Acknowledgements}

We thank Vladimir Tikhonov, Laboratory of Physiologically Active Biopolymers, A. N. Nesmeyanov Institute of Organoelement Compounds, Russian Academy of Sciences, Moscow, Russia for chitosan oligosaccharide; Anna Soltyk, for technical advice on the microarray experiments; Nikko Torres for advice in synergy assay; Charlie Boone and Sarah Barker for strains. Lab members of Bioinformatics and Genomics at Prince Felipe Research Centre, Plant Pathology at U. Alicante and the HIP-HOP and Westwood labs at the U. Toronto for helpful advice and discussions.

This work was funded by grants from the NHGRI to CN and GG, Canadian Institutes for Health Research (CIHR, 84305) to CN, CIHR (81340) to GG and from the Canadian Cancer Society (\#020380) and Natural Science and Engineering Research Council (NSERC) Canada Discovery Grant (138234-06) to JTW. MDLAJ was supported by a Consejo Nacional de Ciencia y Tecnologia (CONACYT) postgraduate Doctoral scholarship. The funders had no role in study design, data collection and analysis, decision to publish, or preparation of the manuscript.

\section{Author details}

${ }^{1}$ Department of Cell and Systems Biology, University of Toronto, Mississauga, Ontario, Canada. ${ }^{2}$ Laboratory of Plant Pathology, Multidisciplinary Institute for Environmental Studies (MIES) Ramon Margalef, Department of Marine Sciences and Applied Biology, University of Alicante, Alicante, Spain. ${ }^{3}$ Bioinformatics and Genomics Department, Prince Felipe Research Centre, Valencia, Spain. ${ }^{4}$ Department of Molecular Genetics, University of Toronto, Toronto, Ontario, Canada. ${ }^{5}$ Stanford Genome Technology Center, Palo Alto, California, USA. ${ }^{6}$ Department of Pharmaceutical Sciences, University of Toronto, Toronto, Ontario, Canada. ${ }^{7}$ Terrence Donnelly Centre for Cellular and Biomedical Research, University of Toronto, Toronto, Ontario, Canada. ${ }^{8}$ Banting and Best Department of Medical Research, University of Toronto, Toronto, Ontario, Canada.

Received: 4 January 2012 Accepted: 25 April 2012

Published: 22 June 2012

\section{References}

1. Kumar M: A review of chitin and chitosan applications. React Funct Polym 2000, 46:1-27.

2. Hayes M, Carney B, Slater J, Bruck W: Mining marine shellfish wastes for bioactive molecules: chitin and chitosan-Part A: extraction methods. Biotechnol J 2008, 3:871-877.

3. Bartnicki-Garcia S: Cell wall chemistry, morphogenesis, and taxonomy of fungi. Annu Rev Microbiol 1968, 22:87-108.

4. Ruiz-Herrera J, Gonzalez-Prieto JM, Ruiz-Medrano R: Evolution and phylogenetic relationships of chitin synthases from yeasts and fungi. FEMS Yeast Res 2002, 1:247-256

5. Kurita K: Chitin and chitosan: functional biopolymers from marine crustaceans. Mar Biotechnol (NY) 2006, 8:203-226.

6. Kim SK, Rajapakse N: Enzymatic production and biological activities of chitosan oligosaccharides (COS): A review. Carbohyd Polym 2005, 62:357-368.

7. Allan $C R$, Hadwiger $L A$ : The fungicidal effect of chitosan on fungi of varying cell wall composition. Exp Mycol 1979, 3:285-287.

8. Palma-Guerrero J, Larriba E, Güerri-Agulló B, Jansson H-B, Salinas J, LopezLlorca LV: Chitosan increases conidiation in fungal pathogens of invertebrates. Appl Microbiol Biot 2010, 87:2237-2245. 
9. Hirano S, Nagao N: Effects of chitosan, pectic acid, lysozyme, and chitinase on the growth of several phytopathogens. Agric Biol Chem 1989, 53:2.

10. El Ghaouth A, Arul J, Asselin A, Benhamou N: Antifungal activity of chitosan on post-harvest pathogens: induction of morphological and cytological alterations in Rhizopus stolonifer. Mycol Res 1992, 769.

11. Benhamou N, Lafontaine PJ, Nicole M: Induction of systemic resistance to Fusarium crown and root rot in tomato plants by seed treatment with chitosan. Phytopathology 1994, 84:1432-1444.

12. Laflamme P, Benhamou N, Bussieres G, Dessureault M: Differential effect of chitosan on root rot fungal pathogens in forest nurseries. Can J Bot 1999, 77:1460-1468.

13. Hadwiger LA, Beckman JM: Chitosan as a component of pea-Fusarium solani interactions. Plant Physiol 1980, 66:205-211.

14. Plascencia-Jatomea M, Viniegra G, Olayo R, Castillo-Ortega MM, Shirai K: Effect of chitosan and temperature on spore germination of Aspergillus niger. Macromol Biosci 2003, 3:582-586.

15. Reddy MVB, Arul J, Ait-Barka E, Angers P, Richard C, Castaigne F: Effect of chitosan on growth and toxin production by Alternaria alternata f. sp. lycopersici. Biocontrol Sci Techn 1998, 8:33-43.

16. Mellegard H, Strand SP, Christensen BE, Granum PE, Hardy SP: Antibacterial activity of chemically defined chitosans: Influence of molecular weight, degree of acetylation and test organism. Int J Food Microbiol 2011, 148:48-54

17. Stössel P, Leuba JL: Effect of chitosan, chitin and some aminosugars on growth of various soilborne phytopathogenic fungi. J Phytopathol 1984, 111:82-90.

18. Liu H, Du Y, Wang $X$, Sun L: Chitosan kills bacteria through cell membrane damage. Int J Food Microbiol 2004, 95:147-155.

19. Liu XF, Guan YL, Yang DZ, Li Z, De Yao K: Antibacterial action of chitosan and carboxymethylated chitosan. J Appl Polym Sci 2001, 79:1324-1335.

20. Tikhonov V, Stepnova E, Babak V, Yamskov I, Palma-Guerrero J, Jansson H, Lopez-Llorca L, Salinas J, Gerasimenko D, Avdienko I, Varlamov V: Bactericidal and antifungal activities of a low molecular weight chitosan and its N-/2(3)-(dodec-2-enyl)succinoyl/-derivatives. Carbohyd Polym 2006, 64:66-72.

21. Helander IM, Nurmiaho-Lassila EL, Ahvenainen R, Rhoades J, Roller S: Chitosan disrupts the barrier properties of the outer membrane of gramnegative bacteria. Int J Food Microbiol 2001, 71:235-244.

22. Zakrzewska A, Boorsma A, Brul S, Hellingwerf KJ, Klis FM: Transcriptional response of Saccharomyces cerevisiae to the plasma membraneperturbing compound chitosan. Eukaryot Cell 2005, 4:703-715.

23. Zakrzewska A, Boorsma A, Delneri D, Brul S, Oliver SG, Klis FM: Cellular processes and pathways that protect Saccharomyces cerevisiae cells against the plasma membrane-perturbing compound chitosan. Eukaryot Cell 2007, 6:600-608.

24. Ericson E, Hoon S, St Onge RP, Giaever G, Nislow C: Exploring gene function and drug action using chemogenomic dosage assays. Methods Enzymol 2010, 470:233-255.

25. Hoon S, Smith AM, Wallace IM, Suresh S, Miranda M, Fung E, Proctor M, Shokat KM, Zhang C, Davis RW, et al: An integrated platform of genomic assays reveals small-molecule bioactivities. Nat Chem Biol 2008, 4:498-506.

26. Giaever G, Flaherty P, Kumm J, Proctor M, Nislow C, Jaramillo DF, Chu AM, Jordan MI, Arkin AP, Davis RW: Chemogenomic profiling: identifying the functional interactions of small molecules in yeast. Proc Natl Acad Sci US A 2004, 101:793-798.

27. Amor JC, Horton JR, Zhu X, Wang Y, Sullards C, Ringe D, Cheng X, Kahn RA Structures of yeast ARF2 and ARL1: distinct roles for the $N$ terminus in the structure and function of ARF family GTPases. J Biol Chem 2001 276:42477-42484.

28. Lee FJ, Huang CF, Yu WL, Buu LM, Lin CY, Huang MC, Moss J, Vaughan M: Characterization of an ADP-ribosylation factor-like 1 protein in Saccharomyces cerevisiae. J Biol Chem 1997, 272:30998-31005.

29. Subramanian A, Tamayo P, Mootha VK, Mukherjee S, Ebert BL, Gillette MA, Paulovich A, Pomeroy SL, Golub TR, Lander ES, Mesirov JP: Gene set enrichment analysis: a knowledge-based approach for interpreting genome-wide expression profiles. Proc Natl Acad Sci U S A 2005, 102:15545-15550

30. Magtanong L, Ho CH, Barker SL, Jiao W, Baryshnikova A, Bahr S, Smith AM, Heisler LE, Choy JS, Kuzmin E, et al: Dosage suppression genetic interaction networks enhance functional wiring diagrams of the cell. Nat Biotechnol 2011, 29:505-511.

31. Martin-Yken H, Dagkessamanskaia A, De Groot P, Ram A, Klis F, Francois J: Saccharomyces cerevisiae YCRO17c/CWH43 encodes a putative sensor/ transporter protein upstream of the BCK2 branch of the PKC1dependent cell wall integrity pathway. Yeast 2001, 18:827-840.

32. Lee KS, Irie K, Gotoh Y, Watanabe Y, Araki H, Nishida E, Matsumoto K, Levin DE: A yeast mitogen-activated protein kinase homolog (Mpk1p) mediates signalling by protein kinase C. Mol Cell Biol 1993, 13:3067-3075.

33. Flandez M, Cosano IC, Nombela C, Martin H, Molina M: Reciprocal regulation between Slt2 MAPK and isoforms of Msg5 dual-specificity protein phosphatase modulates the yeast cell integrity pathway. J Biol Chem 2004, 279:11027-11034.

34. Nordle AK, Rios P, Gaulton A, Pulido R, Attwood TK, Tabernero L: Functional assignment of MAPK phosphatase domains. Proteins 2007, 69:19-31.

35. Medina I, Carbonell J, Pulido L, Madeira SC, Goetz S, Conesa A, Tárraga J, Pascual-Montano A, Nogales-Cadenas R, Santoyo J, et al: Babelomics: an integrative platform for the analysis of transcriptomics, proteomics and genomic data with advanced functional profiling. Nucleic Acids Res 2010, 38:W210-W213.

36. Al-Shahrour F, Carbonell J, Minguez P, Goetz S, Conesa A, Tárraga J, Medina I, Alloza E, Montaner D, Dopazo J: Babelomics: advanced functional profiling of transcriptomics, proteomics and genomics experiments. Nucleic Acids Res 2008, 36:W341-W346.

37. Thevissen K, Terras FR, Broekaert WF: Permeabilization of fungal membranes by plant defensins inhibits fungal growth. Appl Environ Microbiol 1999, 65:5451-5458.

38. Berry DB, Gasch AP: Stress-activated genomic expression changes serve a preparative role for impending stress in yeast. Mol Biol Cell 2008, 19:4580-4587

39. Roberts CJ, Nelson B, Marton MJ, Stoughton R, Meyer MR, Bennett HA, He YD, Dai H, Walker WL, Hughes TR, et al: Signaling and circuitry of multiple MAPK pathways revealed by a matrix of global gene expression profiles. Science 2000, 287:873-880.

40. Ostrosky-Zeichner L, Casadevall A, Galgiani JN, Odds FC, Rex JH: An insight into the antifungal pipeline: selected new molecules and beyond. Nat Rev Drug Discov 2010, 9:719-727.

41. Kong M, Chen XG, Xing K, Park HJ: Antimicrobial properties of chitosan and mode of action: A state of the art review. Int J Food Microbiol 2010, 144:51-63.

42. Xia W, Liu P, Zhang J, Chen J: Biological activities of chitosan and chitooligosaccharides. Food Hydrocolloids 2011, 25:170-179.

43. Pierce SE, Davis RW, Nislow C, Giaever G: Genome-wide analysis of barcoded Saccharomyces cerevisiae gene-deletion mutants in pooled cultures. Nat Protoc 2007, 2:2958-2974.

44. Munson AM, Haydon DH, Love SL, Fell GL, Palanivel VR, Rosenwald AG: Yeast ARL1 encodes a regulator of $\mathrm{K}+$ influx. J Cell Sci 2004, 117:2309-2320.

45. Munro S: The Arf-like GTPase Arl1 and its role in membrane traffic. Biochem Soc Trans 2005, 33:601-605.

46. Marešová L, Sychrová H: Genetic interactions among the Arl1 GTPase and intracellular $\mathrm{Na}(+) / \mathrm{H}(+)$ antiporters in $\mathrm{pH}$ homeostasis and cation detoxification. FEMS Yeast Res 2010, 10:802-811.

47. Rosenwald AG, Rhodes MA, Van Valkenburgh H, Palanivel V, Chapman G, Boman A, Zhang CJ, Kahn RA: ARL1 and membrane traffic in Saccharomyces cerevisiae. Yeast 2002, 19:1039-1056.

48. Bonangelino CJ, Chavez EM, Bonifacino JS: Genomic screen for vacuolar protein sorting genes in Saccharomyces cerevisiae. Mol Biol Cell 2002, 13:2486-2501

49. Lomize AL, Pogozheva ID, Lomize MA, Mosberg HI: Positioning of proteins in membranes: a computational approach. Protein Sci 2006, 15:1318-1333.

50. Lomize MA, Lomize AL, Pogozheva ID, Mosberg HI: OPM: orientations of proteins in membranes database. Bioinformatics 2006, 22:623-625.

51. Palma-Guerrero J, Lopez-Jimenez JA, Pérez-Berná AJ, Huang I-C, Jansson H-B, Salinas J, Villalaín J, Read ND, Lopez-Llorca LV: Membrane fluidity determines sensitivity of filamentous fungi to chitosan. Mol Microbiol 2010, 75:1021-1032.

52. Opekarova M, Malinsky J, Tanner W: Plants and fungi in the era of heterogeneous plasma membranes. Plant Biol (Stuttg) 2010, 12(Suppl 1):94-98. 
53. Hardie DG, Carling D: The AMP-activated protein kinase-fuel gauge of the mammalian cell? Eur J Biochem 1997, 246:259-273.

54. Palma-Guerrero J, Huang I-C, Jansson H-B, Salinas J, Lopez-Llorca LV, Read ND: Chitosan permeabilizes the plasma membrane and kills cells of Neurospora crassa in an energy dependent manner. Fungal Genet Biol 2009, 46:585-594.

55. Palma-Guerrero J, Jansson H-B, Salinas J, Lopez-Llorca LV: Effect of chitosan on hyphal growth and spore germination of plant pathogenic and biocontrol fungi. J Appl Microbiol 2008, 104:541-553.

56. Gomez-Rivas L, Escudero-Abarca BI, Aguilar-Uscanga MG, Hayward-Jones PM, Mendoza P, Ramirez M: Selective antimicrobial action of chitosan against spoilage yeasts in mixed culture fermentations. J Ind Microbiol Biotechnol 2004, 31:16-22.

57. Hillenmeyer ME, Fung E, Wildenhain J, Pierce SE, Hoon S, Lee W, Proctor M, St Onge RP, Tyers M, Koller D, et al: The chemical genomic portrait of yeast: uncovering a phenotype for all genes. Science 2008, 320:362-365.

58. Sheehan DJ, Hitchcock CA, Sibley CM: Current and emerging azole antifungal agents. Clin Microbiol Rev 1999, 12:40-79.

59. Odds FC, Brown AJ, Gow NA: Antifungal agents: mechanisms of action. Trends Microbiol 2003, 11:272-279.

60. Gruszecki WI, Gagos M, Herec M, Kernen P: Organization of antibiotic amphotericin B in model lipid membranes. A mini review. Cell Mol Biol Lett 2003, 8:161-170.

61. Brajtburg J, Powderly WG, Kobayashi GS, Medoff G: Amphotericin B: current understanding of mechanisms of action. Antimicrob Agents Chemother 1990, 34:183-188.

62. Bottema CK, Parks LW: Delta14-sterol reductase in Saccharomyces cerevisiae. Biochim Biophys Acta 1978, 531:301-307.

63. Burke D: Methods in yeast genetics: a Cold Spring Harbor Laboratory course manual. Plainview, N.Y.: Cold Spring Harbor Laboratory Press; 2000

64. Gietz RD, Schiestl RH: Large-scale high-efficiency yeast transformation using the LiAc/SS carrier DNA/PEG method. Nat Protoc 2007, 2:38-41.

65. Chomczynski P, Sacchi N: Single-step method of RNA isolation by acid guanidinium thiocyanate-phenol-chloroform extraction. Anal Biochem 1987, 162:156-159.

66. Carvalho BS, Irizarry RA: A framework for oligonucleotide microarray preprocessing. Bioinformatics 2010, 26:2363-2367.

67. Smyth G, Thorne N, Wettenhall J: Limma: linear models for microarray data user's guide. Software manual available from http://www bioconductor org 2003.

68. Edgar R, Domrachev M, Lash AE: Gene Expression Omnibus: NCBI gene expression and hybridization array data repository. Nucleic Acids Res 2002, 30:207-210

69. Eisen MB, Spellman PT, Brown PO, Botstein D: Cluster analysis and display of genome-wide expression patterns. Proc Natl Acad Sci U S A 1998, 95:14863-14868.

70. de Hoon MJ, Imoto S, Nolan J, Miyano S: Open source clustering software. Bioinformatics 2004, 20:1453-1454.

71. Saldanha AJ: Java Treeview-extensible visualization of microarray data. Bioinformatics 2004, 20:3246-3248.

72. Benschop JJ, Brabers N, van Leenen D, Bakker LV, van Deutekom HW, van Berkum NL, Apweiler E, Lijnzaad P, Holstege FC, Kemmeren P: A consensus of core protein complex compositions for Saccharomyces cerevisiae. Mol Cell 2010, 38:916-928.

73. Merico D, Isserlin R, Stueker O, Emili A, Bader GD: Enrichment map: a network-based method for gene-set enrichment visualization and interpretation. PLoS One 2010, 5:e13984.

74. Smoot ME, Ono K, Ruscheinski J, Wang PL, Ideker T: Cytoscape 2.8: new features for data integration and network visualization. Bioinformatics 2011, 27:431-432.

75. Gasch AP, Spellman PT, Kao CM, Carmel-Harel O, Eisen MB, Storz G, Botstein $D$, Brown PO: Genomic expression programs in the response of yeast cells to environmental changes. Mol Biol Cell 2000, 11:4241-4257.

76. Rozen S, Skaletsky H: Primer3 on the WWW for general users and for biologist programmers. Methods Mol Biol 2000, 132:365-386.

\section{Submit your next manuscript to BioMed Central and take full advantage of:}

- Convenient online submission

- Thorough peer review

- No space constraints or color figure charges

- Immediate publication on acceptance

- Inclusion in PubMed, CAS, Scopus and Google Scholar

- Research which is freely available for redistribution 